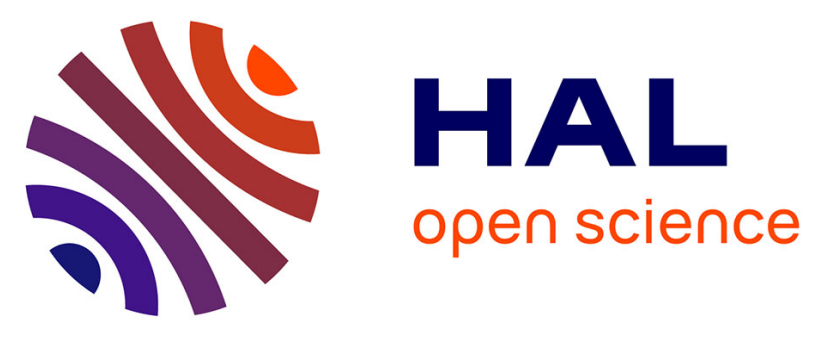

\title{
Model intercomparison in the Mediterranean: MEDMEX simulations of the seasonal cycle
}

Jean-Marie Beckers, Michel Rixen, Pierre Brasseur, Jean-Michel Brankart, Abdelali El Moussaoui, Michel Crépon, Christophe Herbaut, Françoise Martel, F. van den Berghe, Laurent Mortier, et al.

\section{To cite this version:}

Jean-Marie Beckers, Michel Rixen, Pierre Brasseur, Jean-Michel Brankart, Abdelali El Moussaoui, et al.. Model intercomparison in the Mediterranean: MEDMEX simulations of the seasonal cycle. Journal of Marine Systems, 2002, 33-34, pp.215-251. 10.1016/S0924-7963(02)00060-X . hal-00212009

\section{HAL Id: hal-00212009 \\ https://hal.science/hal-00212009}

Submitted on 14 Mar 2020

HAL is a multi-disciplinary open access archive for the deposit and dissemination of scientific research documents, whether they are published or not. The documents may come from teaching and research institutions in France or abroad, or from public or private research centers.
L'archive ouverte pluridisciplinaire HAL, est destinée au dépôt et à la diffusion de documents scientifiques de niveau recherche, publiés ou non, émanant des établissements d'enseignement et de recherche français ou étrangers, des laboratoires publics ou privés. 


\title{
Model intercomparison in the Mediterranean: MEDMEX simulations of the seasonal cycle
}

\author{
J.-M. Beckers $^{\text {a,* }}{ }^{\text {, M. Rixen }}{ }^{\text {a }}$, P. Brasseur ${ }^{\text {b }}$, J.-M. Brankart ${ }^{\text {b }}$, A. Elmoussaoui ${ }^{\text {a }}$,
} M. Crépon ${ }^{c}$, Ch. Herbaut ${ }^{c}$, F. Martel ${ }^{d}$, F. Van den Berghe ${ }^{d}$, L. Mortier $^{c}$,

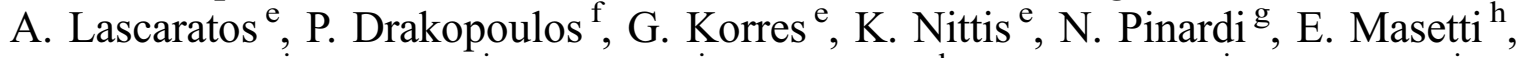

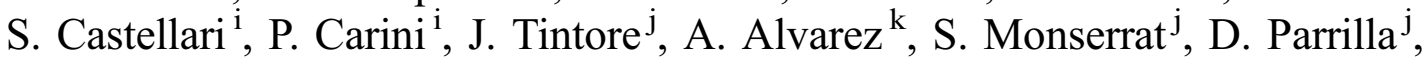
R. Vautard ${ }^{1}$, S. Speich ${ }^{\mathrm{m}}$

\author{
${ }^{\mathrm{a}}$ University of Liège, GHER, Sart-Tilman B5, B-4000 Liège, Belgium \\ ${ }^{\mathrm{b}}$ LEGI-UMR, 5519 du CNRS-Equipe MEOM-BP53X, F-38041 Grenoble Cedex, France \\ ${ }^{\mathrm{C}}$ Laboratoire d'Océanographie Dynamique et de Climatologie, Université Pierre et Marie Curie Tour 26, Boite 1004 , \\ place Jussieu, 75252 Paris Cedex 05, France \\ ${ }^{\mathrm{d}}$ CETIIS, Bat. D, Allée de Beaumanoir 30, Av. Malacrida, 13100 Aix en Provence, France \\ 'Ocean Physics Group, Department of Applied Physics University Campus, Building PHYS-5 Athens, GR-15784 Greece \\ ${ }^{\mathrm{f}}$ Institute of Marine Biology of Crete, P.O. Box 2214 Heraklion 71003 Crete, Greece \\ ${ }^{\mathrm{g}}$ Department of Physics, Bologna University, Viale Berti Pichat 6/2, Bologna, Italy \\ ${ }^{\mathrm{h}}$ ISAO, Via P. Gobetti, 101 C.A.P., 40129 Bologna, Italy \\ i ISAO-CNR Via Gobetti 101, 40129 Bologna, Italy \\ jIMEDEA (CSIC-UIB) Edifici Mateu Orfila i Rotger Campus universitari, E-07071 Palma, Spain \\ ${ }^{\mathrm{k}}$ SACLANT Undersea Research Centre Viale San Bartolomeo, 40019138 La Spezia, Italy \\ ${ }^{1}$ L.M.D. Ecole Polytechnique Ecole Normale Supérieure Université de Paris, 6 F 91128 Palaiseau Cedex, France \\ ${ }^{\mathrm{m}}$ Laboratoire de Physique des Oceans Universite de Bretagne Occidentale UFR Sciences-6, \\ Avenue Le Gorgeu B.P. 80929285 Brest Cedex, France
}

\begin{abstract}
The simulation of the seasonal cycle in the Mediterranean by several primitive equation models is presented. All models were forced with the same atmospheric data, which consists in either a monthly averaged wind-stress with sea surface relaxation towards monthly mean sea surface temperature and salinity fields, or by daily variable European Centre for Medium Range Weather Forecast (ECMWF) reanalysed wind-stress and heat fluxes. In both situations models used the same grid resolution. Results of the modelling show that the model behaviour is similar when the most sensitive parameter, vertical diffusion, is calibrated properly. It is shown that an unrealistic climatic drift must be expected when using monthly averaged forcing functions. When using daily forcings, drifts are modified and more variability observed, but when performing an EOF analysis of the sea surface temperature, it is shown that the basic cycle, represented similarly by the
\end{abstract}

\footnotetext{
* Corresponding author. National Fund for Scientific Research, University of Liège, GHER, Sart-Tilman B5, B-4000 Liège, Belgium. Tel.: +32-4-366-33-58; fax: +32-4-366-23-55.

E-mail address: JM.Beckers@ulg.ac.be (J.-M. Beckers).
} 


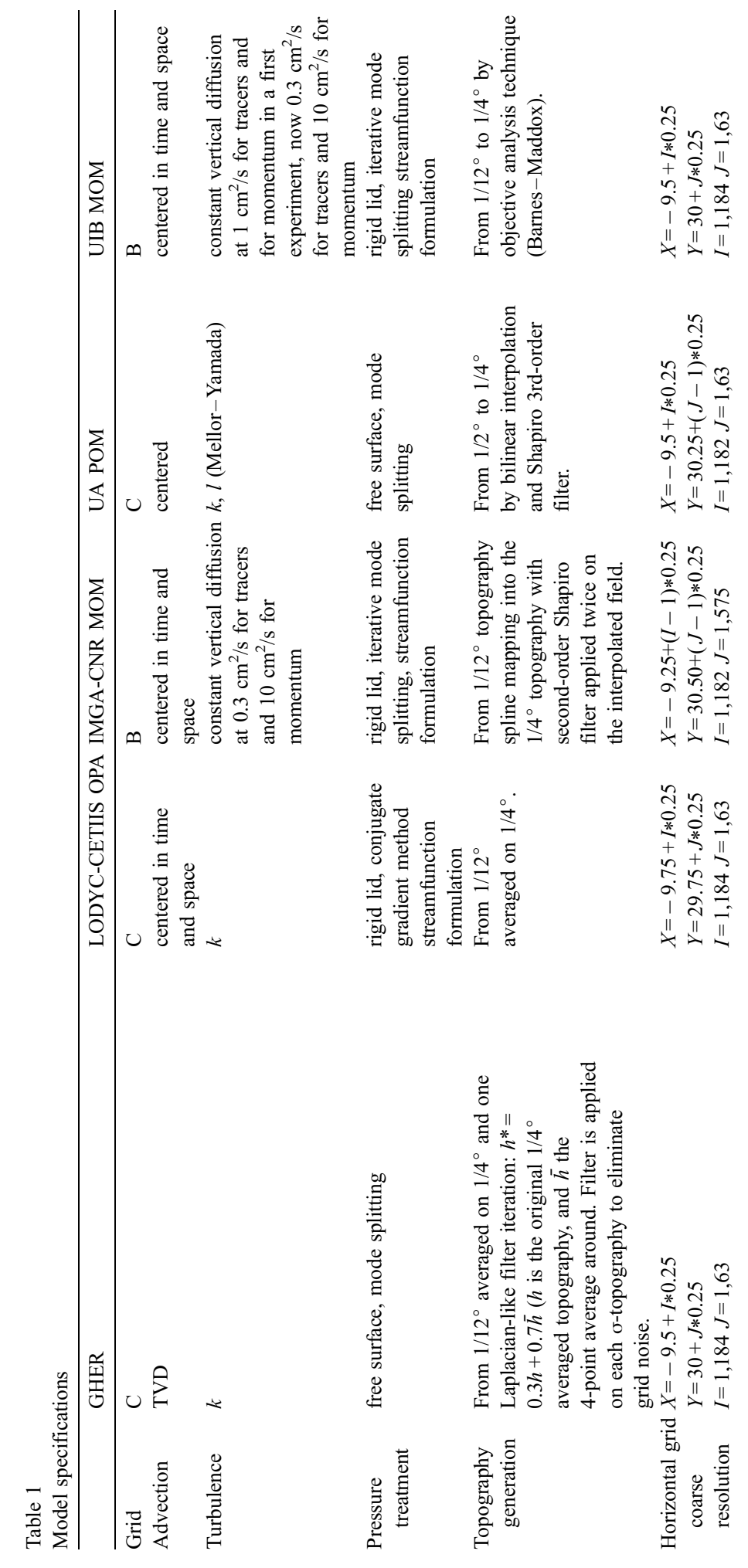




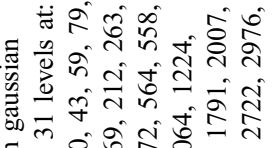

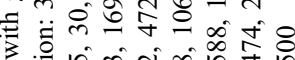

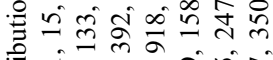

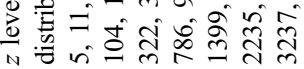

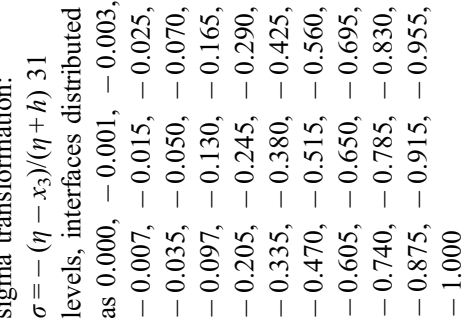

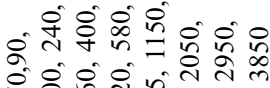

ฉิจ

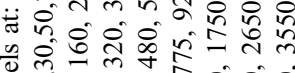

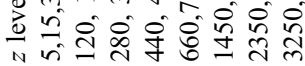

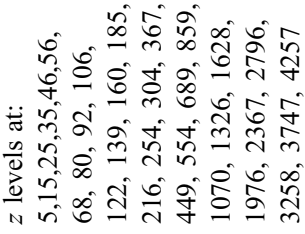

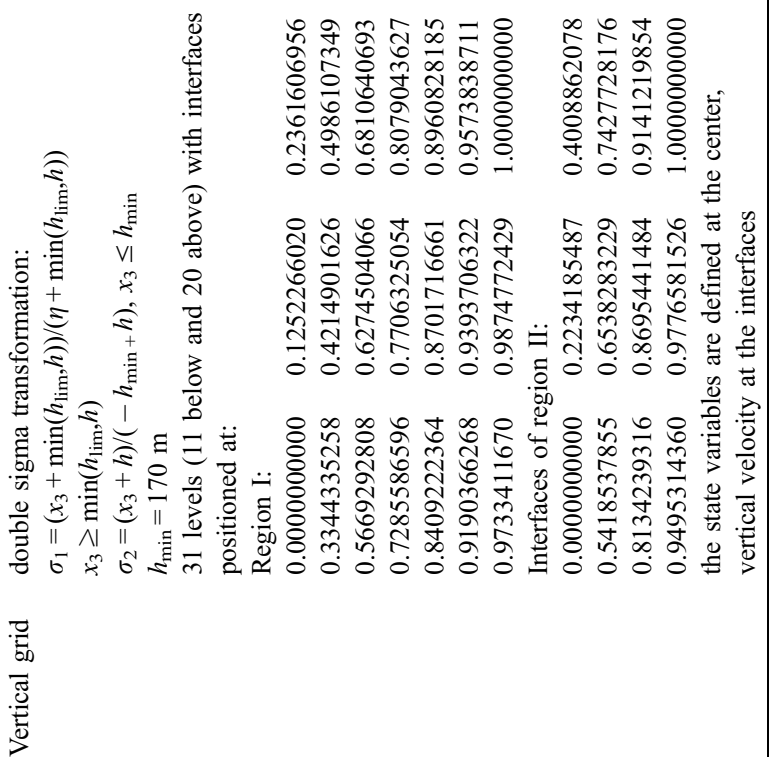




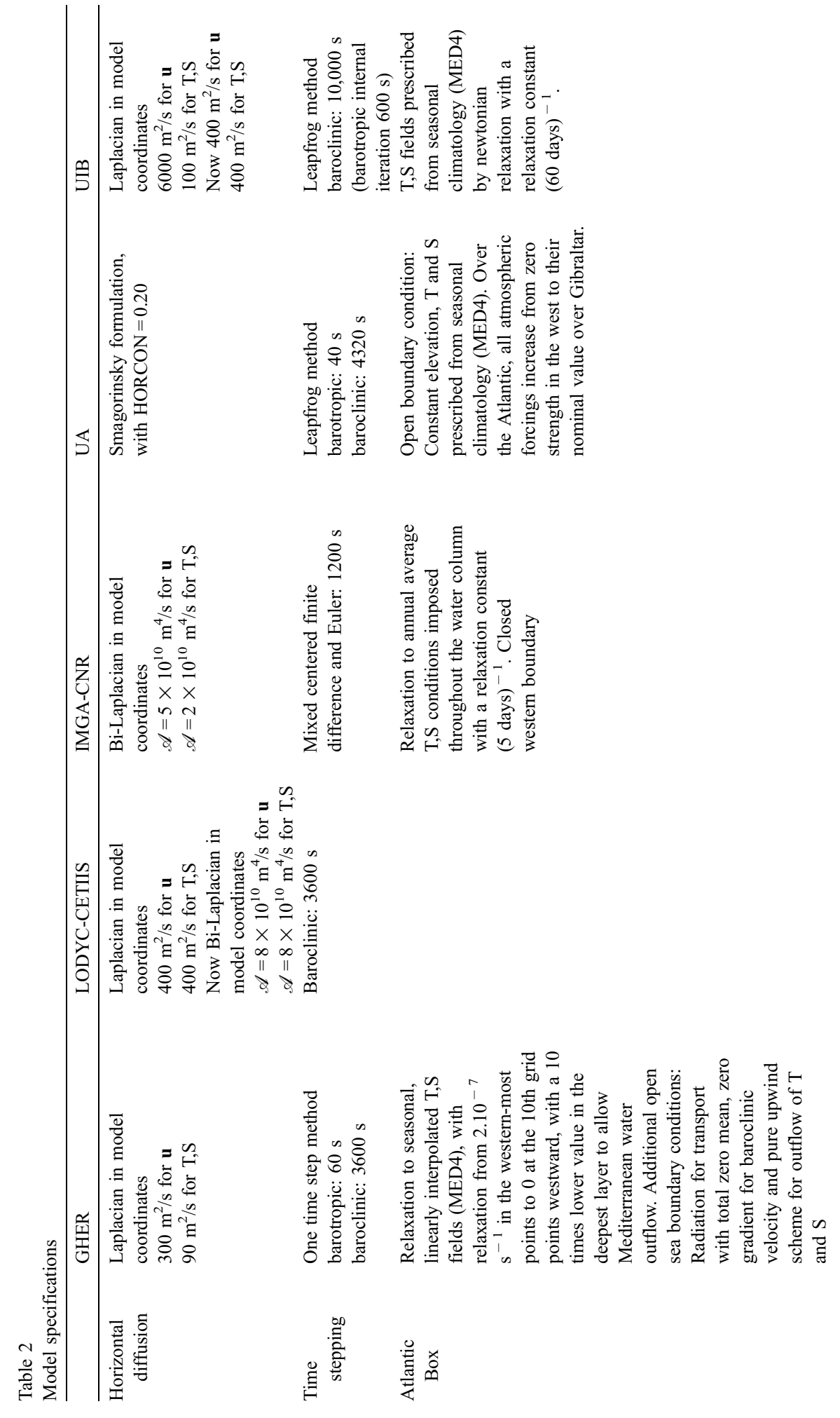




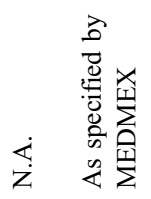

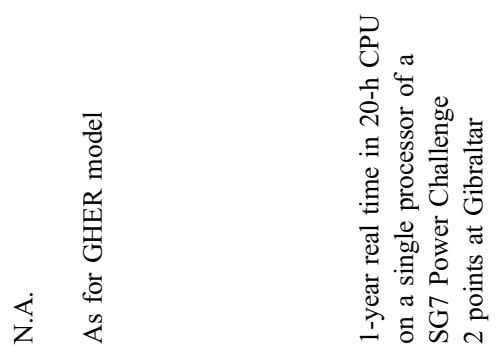

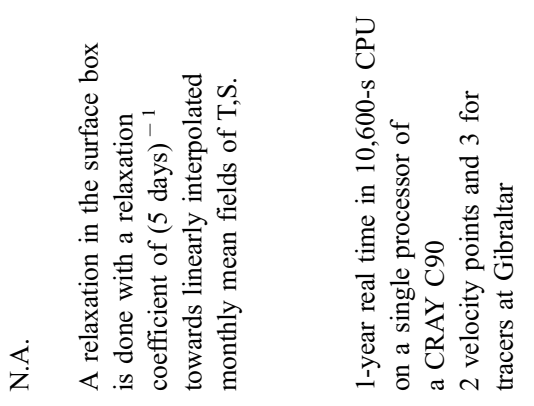

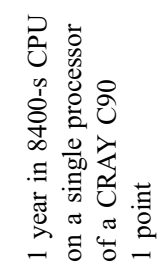

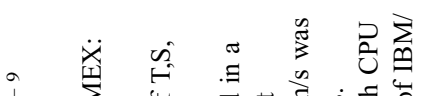

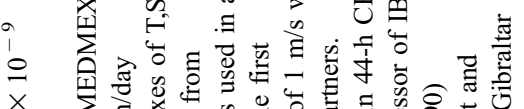

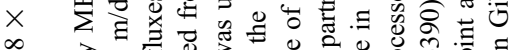

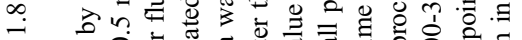

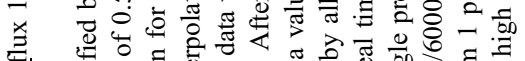

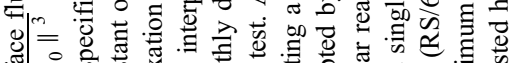

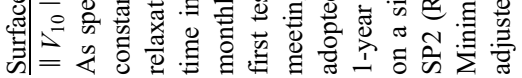

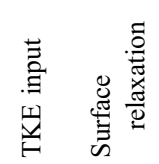

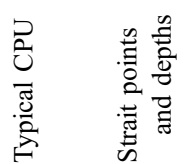


models, consists of the seasonal cycle which accounts for more than $90 \%$ of its variability.

Keywords: Mediterranean; MEDMEX; Seasonal cycle

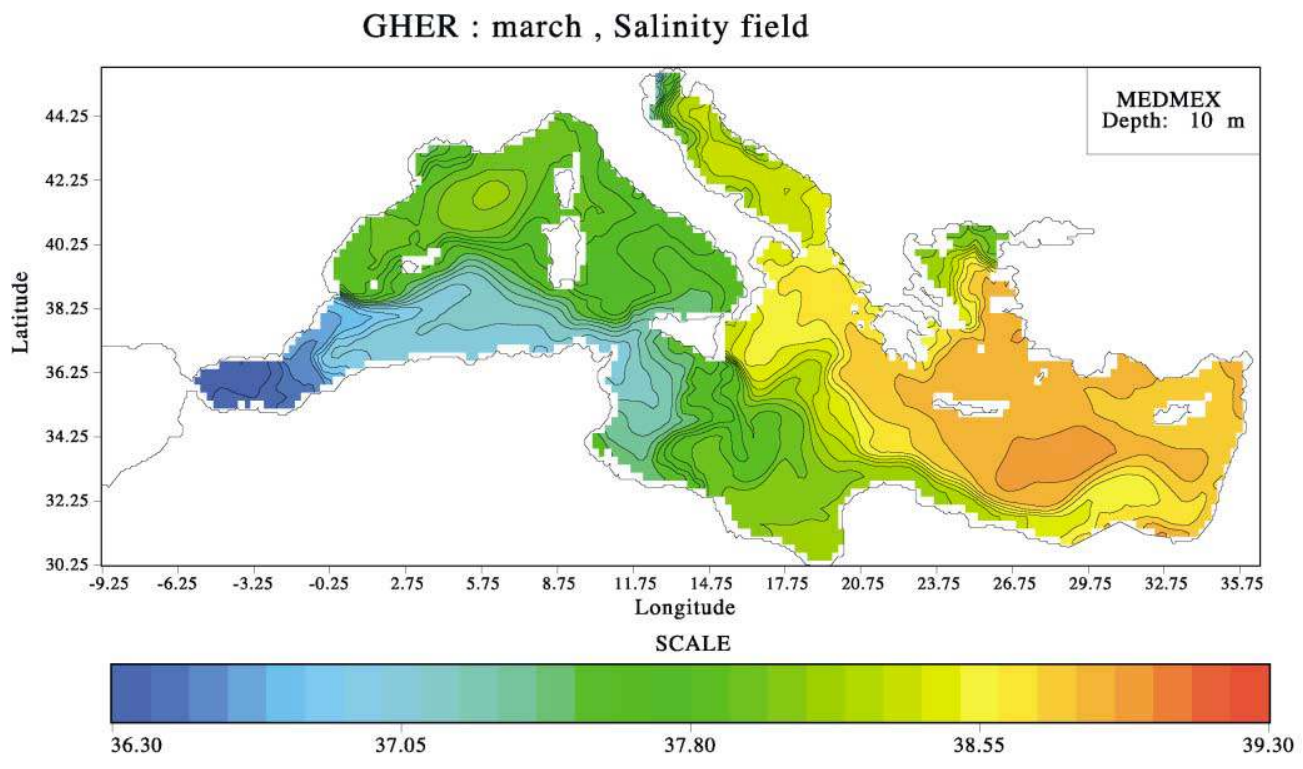

UA : march , Salinity field

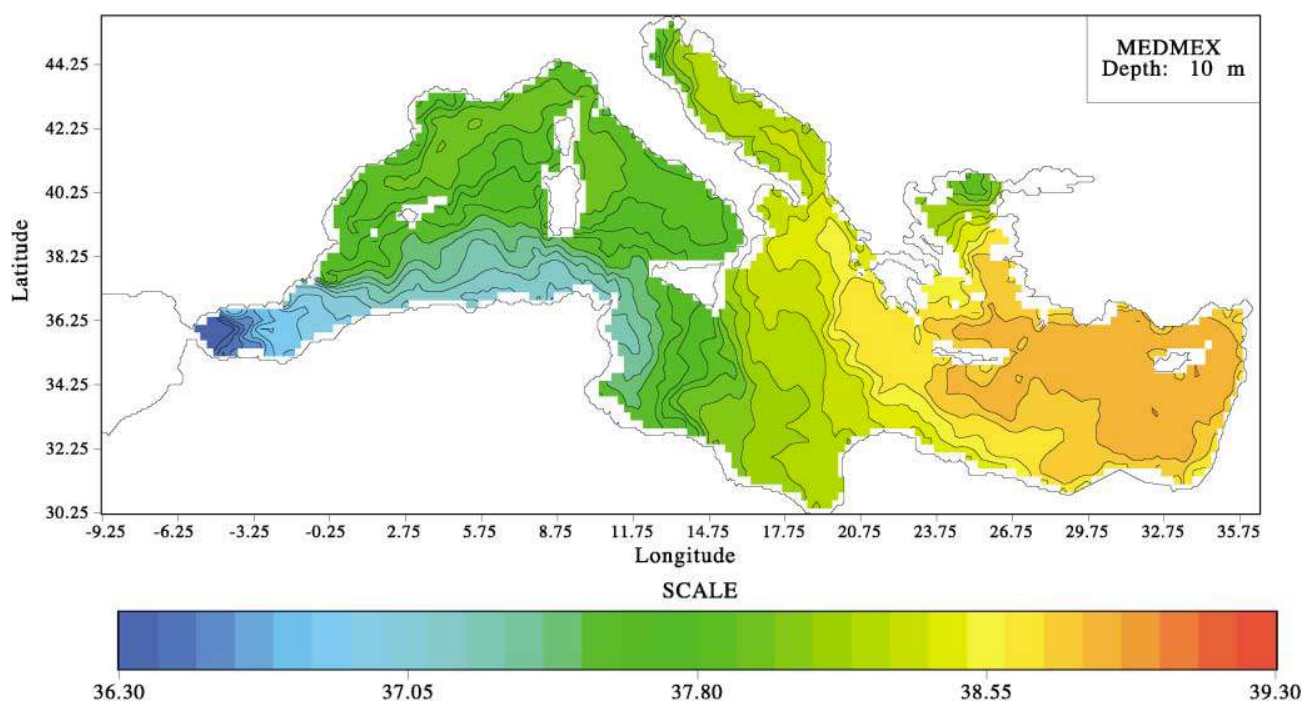

Fig. 1. Salinity fields March average, experiment I. 


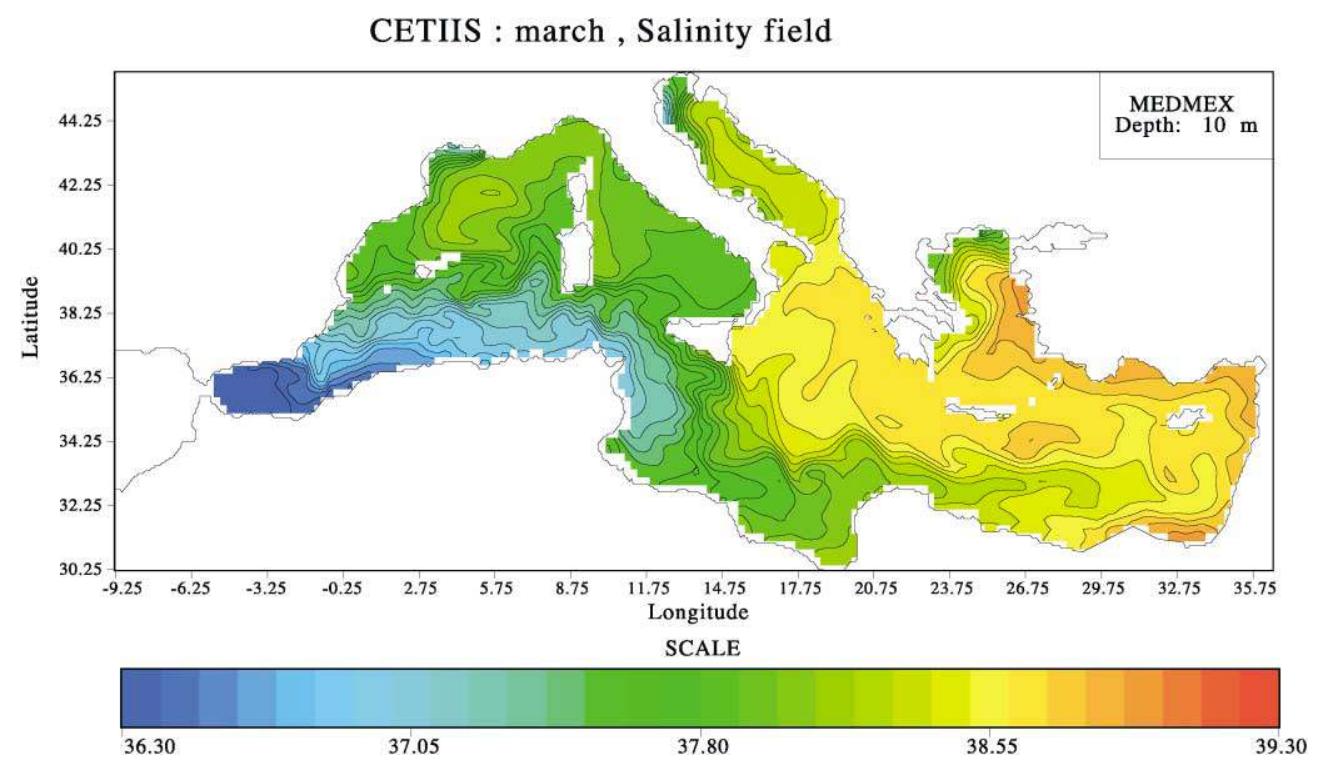

Fig. 1 (continued).

\section{Introduction}

The present paper is an attempt to give a flavour of results obtained during a project aimed at promoting model intercomparison in the Mediterranean Sea.

Prior to the MEDMEX project, extensive modelling exercises had been performed in the Mediterranean Sea (EROS2000, EUROMODEL and MERMAIDS projects with models of Beckers, 1991; EUROMODEL group, 1995; MERMAIDS, 1998), but coordination and comparison between the different modelling aspects was sporadic. Thus, there already exists a series of studies devoted to the modelling of the Mediterranean Sea: Becker (1991) used a $15-\mathrm{km}$ resolution model in the Western Mediterranean to calculate the seasonal cycle, including a relaxation towards MODB (Brasseur et al., 1996) temperature and salinity fields; Zavatarelli and Mellor (1995) used the POM model with curvilinear coordinates on the whole Mediterranean; the OPA model was applied successively to the western Mediterranean and the entire basin (Herbaut et al., 1996, 1998); the GFDL model MOM was implemented on the whole Mediterranean using interactive air-sea fluxes. Haines and Wu (1998) and Roussenov et al. (1995) used the GFDL model with surface relaxation fluxes, while Alvarez et al. (1994) introduced the so-called Neptune effect into the MOM model applied to the Mediterranean. The different approaches to the modelling are still going on. Rather than working on models with resolutions unable to properly resolve the radius of deformation $(25 \mathrm{~km}$ in the Mediterranean), most models currently in use are working at a $1 / 8^{\circ}$ scale (Demirov and Pinardi, 2002; Stratford and Haines, 2002) with emphasis on interannual variations rather than seasonal cycles. However, when the intercomparison was started, it was found necessary to compare the different models on a common basis, in order to provide some estimates on the errors and the most sensitive parameters one could expect for the different models. This is why a formal group was created in which the different modellers would systematically compare their models, which could help improve models and understand their behaviours. The results of the so developed MEDMEX experiment are described hereafter. Updated information and data can be found at: http://modb.oce.ulg.ac.be/MEDMEX.

Model intercomparison already has a relatively long tradition in atmospheric modelling (see for example CMIP http://www.pcmdi.llnl.gov/covey/ cmip/diagsub.html and the AMIP project (Gates et 
al., 1999)), but in ocean sciences, model intercomparison has not been widely used, partly because of the lack of models applied to the same problem, partly because of computational constraints or lack of data for control.

Here we will not intercompare on purely mathematical aspects, e.g. on turbulent closure schemes as done in Davies and Xing (1995), or on a specific numerical aspect as in Baptista et al. (1995) and James (1996). A more general model test situation is chosen, excluding academic test cases, e.g. Røed et al. (1995), Slørdal et al. (1994) or industrial validation of numerical codes (Dee, 1995). A comparison in more complex situations was recently done for coastal ocean models (Haidvogel and Beckmann, 1998), highlighting the difficulty of models to extract small residual signals
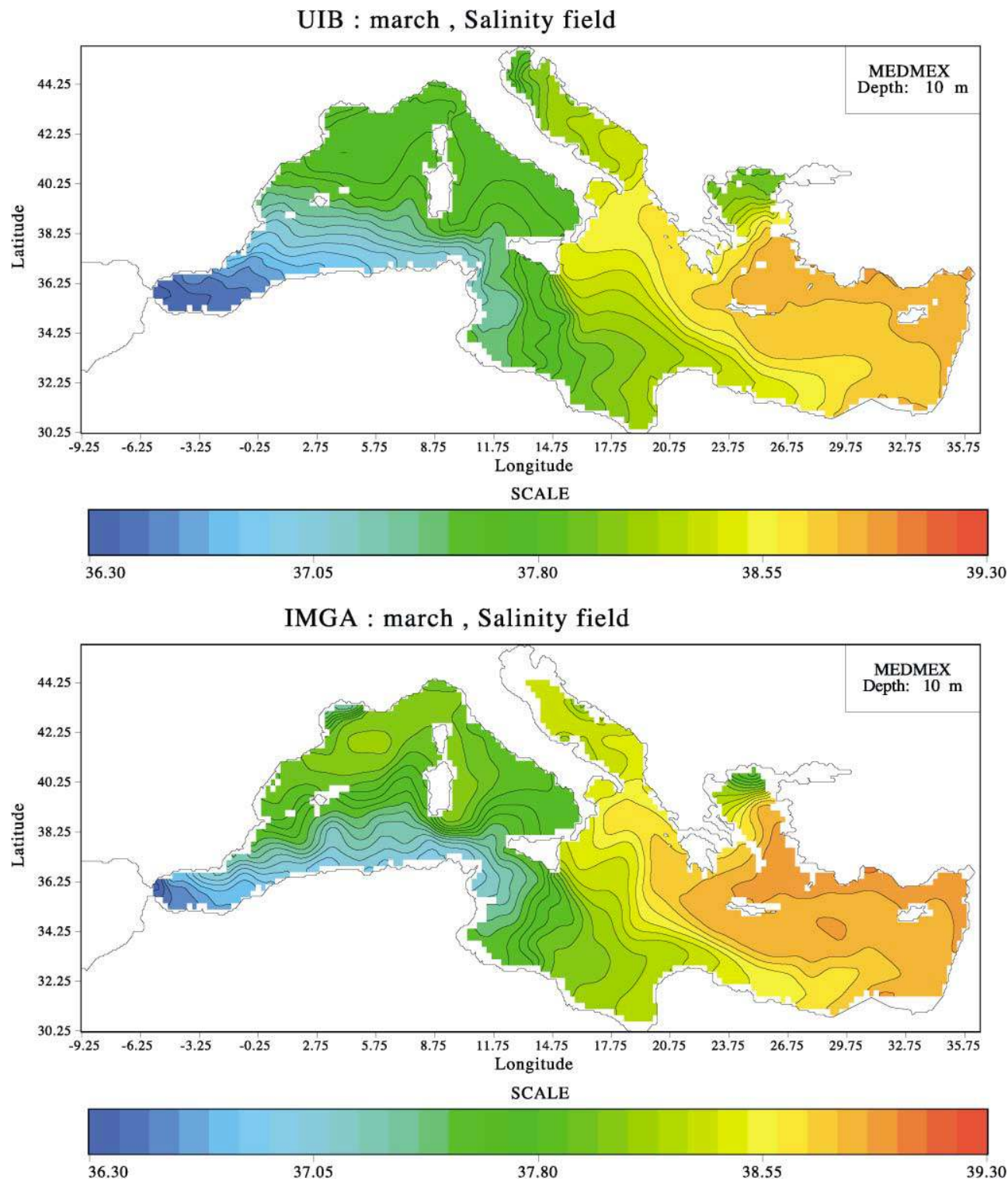

Fig. 2. Salinity fields March average, experiment I. 


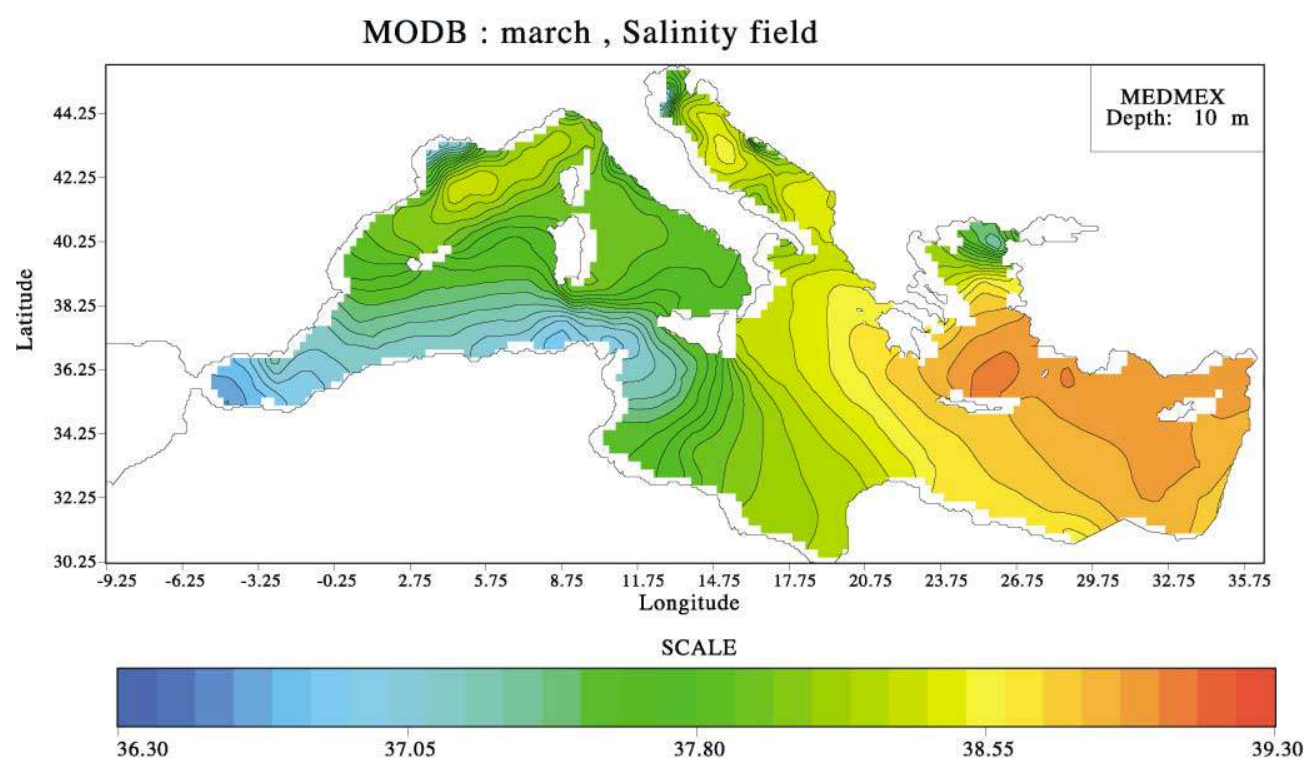

Fig. 2 (continued).

from a periodically forced system with a complicated topography and strong baroclinic structures.

Since for all these intercomparisons in simplified situations it is not obvious to extrapolate the model behaviour when applied to the real case, the focus of the comparison of the model results will be concentrated in the present case on a realistic and complex situation found in the Mediterranean circulation with realistic forcing, where the models should at least resolve the dominant signal in a similar way. This is similar to the tidal flow forum (Werner, 1995) or the NOMADS (Proctor, 1995) approach in the North Sea, except that here a common model configuration is set up specifically for the intercomparison experiment. This choice was a posterior justified by the conclusion of the NOMADS intercomparison project that more relevant information would have been obtained by using the same forcing functions. Of course this requires some additional adjustments and modifications in each of the models already in use for specific purposes; but each model will then use exactly the same specifications so as to simplify a quantitative model intercomparison. Due to the current lack of an appropriate exhaustive observational data set for an independent comparison with data, no skill assessment (Vested et al., 1995) was done. Indeed, the only data set available (climatological hydrography of the MODB/IS MED4 data) contains only hydrography and is partly used to drive the models. Therefore, it cannot be considered completely independent. Furthermore, in deeper layers, data coverage is relatively sparse and the seasonal cycle not necessarily well resolved in the hydrographic data. Therefore, MODB/ IS hydrography is used only for qualitative visual comparison or drift detection in the models, but not for detailed statistical skill analysis.

According to the classification of the AMIP intercomparison group, ${ }^{1}$ the present intercomparison is a level two intercomparison, since it is done in a very realistic situation. Two realistic situations will be analysed. A first experiment deals with the robust simulation of the seasonal cycle by monthly averaged forcings and sea surface relaxation towards observed salinity and temperature fields. In the second experiment, surface forcing is then given on a daily flux basis, leaving the sea surface temperature freely evolving. Note that this means that no feedback between the simulated sea surface and the heat flux

\footnotetext{
${ }^{1}$ See the WWW-server http://www-pcmdi.llnl.gov for more details on the Atmospheric Model Intercomparison Project.
} 
calculation is present, which is a more difficult situation to handle than the interactive flux forcing that includes a stabilising feedback between simulated sea surface temperature and calculated heat flux.

In Section 2, we will outline the setup used for the model intercomparison. Results will then be presented in Sections 3 and 4.

\section{Setup of the comparison}

The model intercomparison was based on the idea that the model should run in such a way that forcing data are identical when possible, in order to avoid any interpretation problem arising from using different forcing functions (a situation which arose in an

GHER : march, velocity

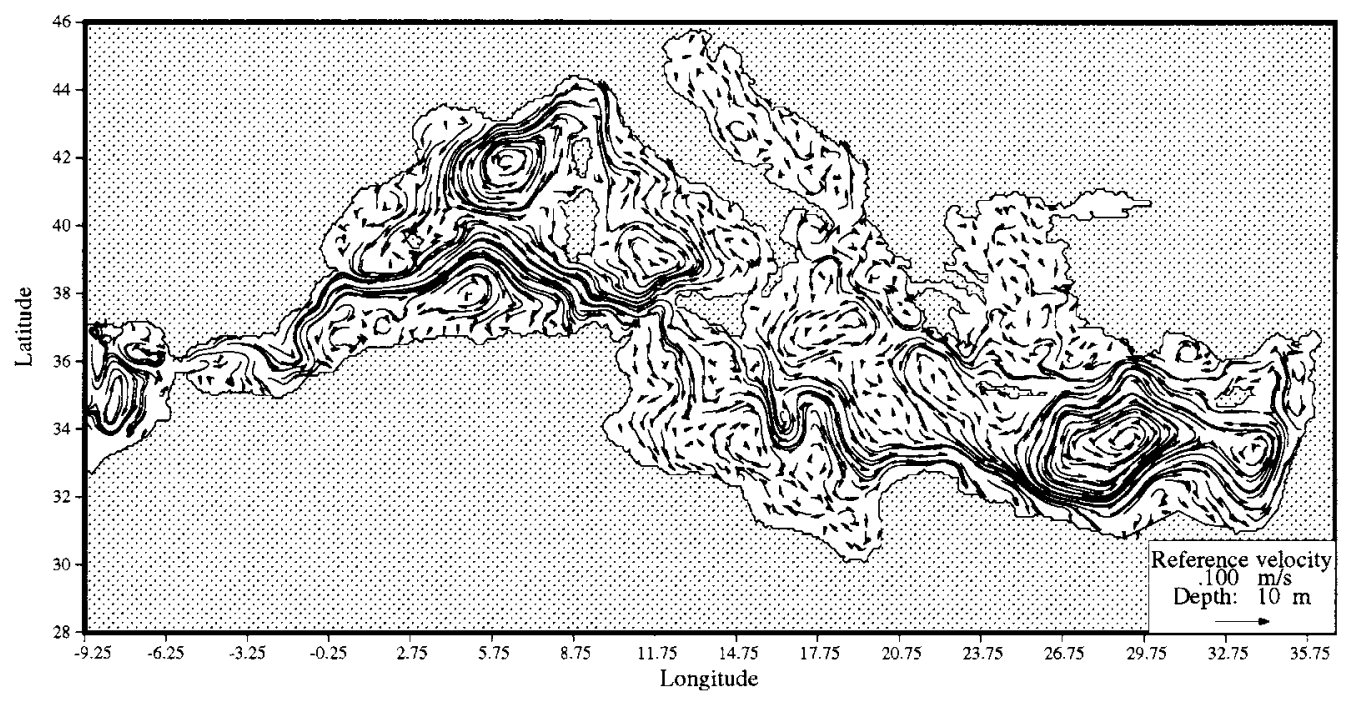

$\mathrm{UA}:$ march , velocity

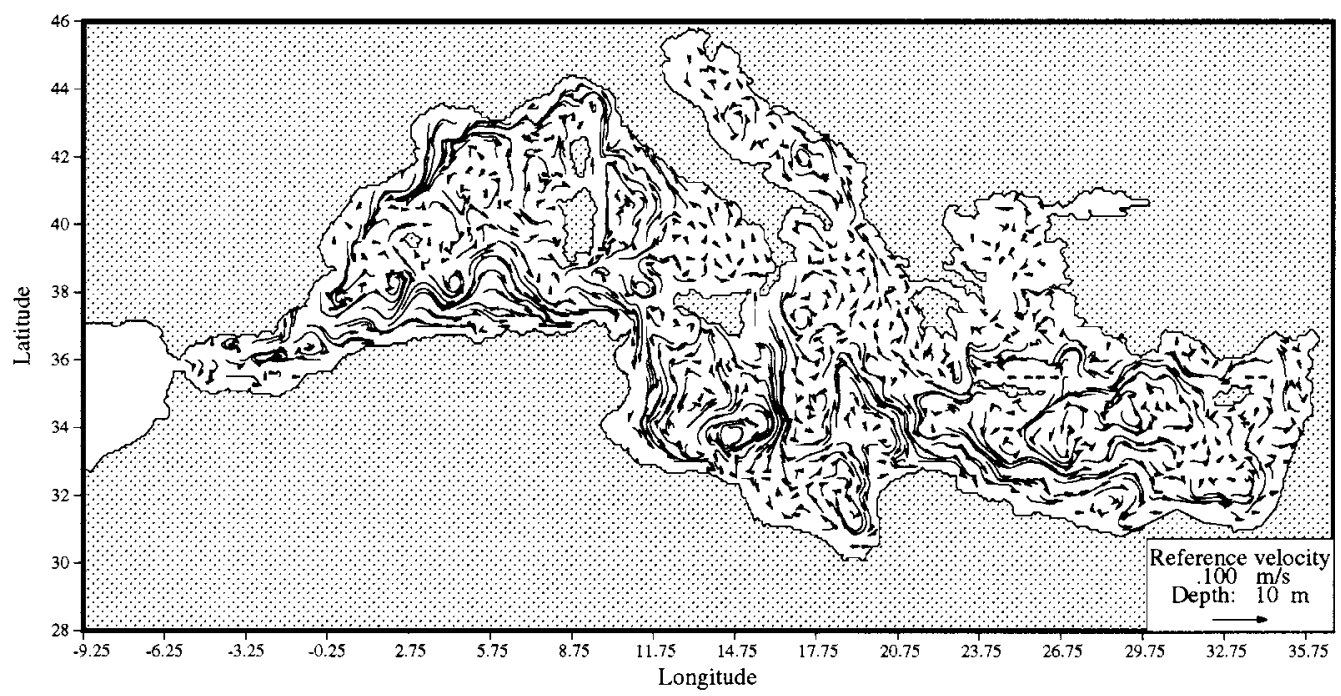

Fig. 3. Velocity fields March Average, experiment I. The vector length in the bottom right inlet corresponds to a velocity of $0.1 \mathrm{~m} / \mathrm{s}$. 


\section{CETIIS : march, velocity}

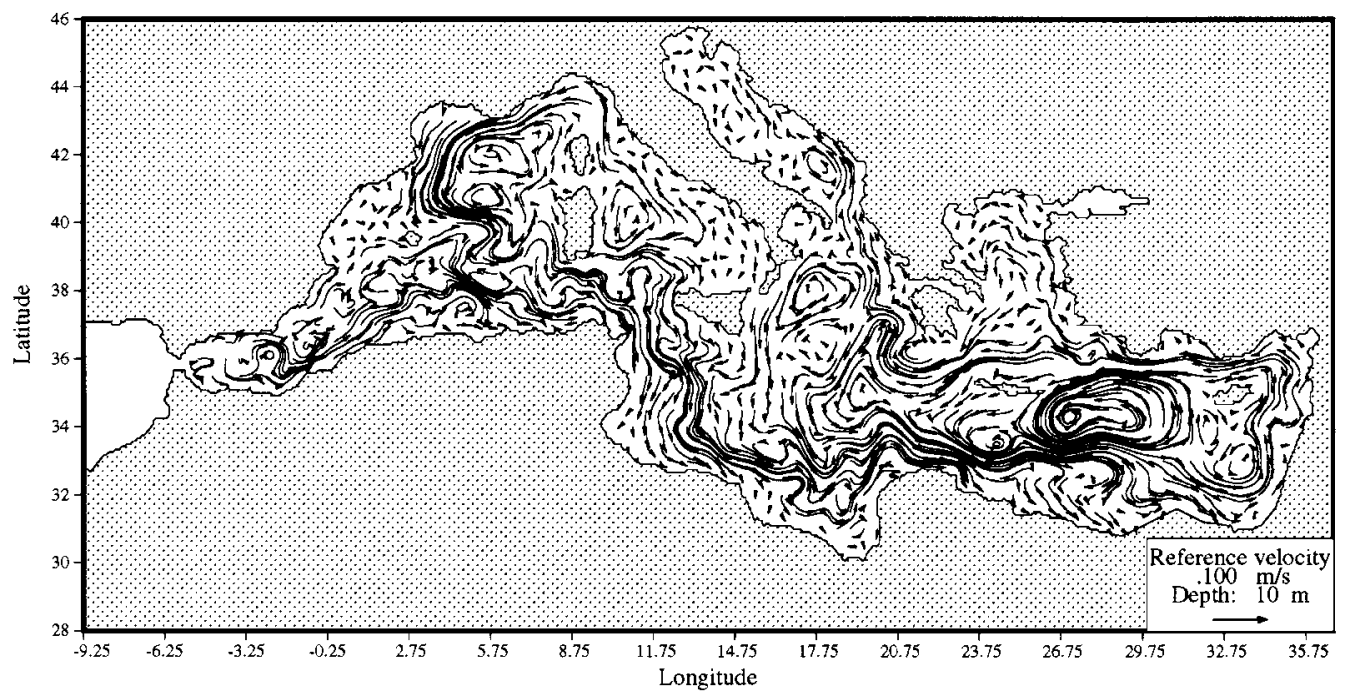

Fig. 3 (continued).

intercomparison experiment for North Sea model, NOMADS; Proctor, 1995).

Atmospheric data for wind-stress were thus identical for all models participating and consisted in either wind-stress fields from European Centre for Medium Range Weather Forecast (ECMWF) daily reanalysed data from the period 1978 to 1993, or monthly averaged wind stress fields obtained by averaging all available wind stress fields for a given month to obtain an estimate of climatological monthly wind stress data. The so obtained fields exhibit the salient features of the forcing like the Mistral and Tramontane, the Bora winds and the northern wind over the Aegean basin. Though the fields exhibit finer structures than the classical fields of Hellerman and Rosenstein (1983), the resolution of $1.25^{\circ}$ is still relatively low and the vorticity inputs over the basin, though clearly present in the data, still call for improvements, if local analyses of the circulation are needed. For the sake of an intercomparison at basin scale, the wind-stress fields are however sufficiently well resolved.

For heat fluxes, either daily ECMWF heat flux over a 15-year period was prescribed or a surface relaxation towards monthly averaged sea surface temperature.
For salt fluxes, the total surface flux of salt $-\tilde{\lambda} \partial S /$ $\partial x_{3}$ can then be imposed by

$-\tilde{\lambda} \frac{\partial S}{\partial x_{3}}=-\frac{S Q^{L}}{\rho_{0} L}+P S+c\left(S-S_{*}\right)$

where $Q^{L}$ is the evaporation diagnosed from the ECMWF latent heat flux, $\rho_{0}$ the density of sea water, $L$ the latent heat capacity and $P$ the monthly climatology of precipitation values as retrieved from Jaeger (1976). This is the forcing for the experiment with daily forcings. For climatological monthly averaged forcings, a surface relaxation of modelled sea salinity $S$ towards climatological sea surface salinity $S_{*}$ is prescribed with the relaxation value $c=1 \mathrm{~m} /$ day.

Each model used the same original topographic data, from which each of the models then creates its own model topography, since the latter depends on the numerical characteristics of the model ( $z$-models for example generally cannot take into account the exact local value of the topography file everywhere, but must accommodate the depth to the nearest $z$ level resolved; B-grids need at least 2 grid points across straits; $\sigma$-coordinate models do not allow for too steep slopes in regions of strong stratifications, etc.). 


\section{General circulation simulated by a monthly mean atmospheric forcing, experiment I}

The first MEDMEX modelling experiment (called experiment I hereafter) was set up to study the behaviour of the models when forced by the classical perpetual year approach, repeating each year the atmospheric data of a monthly averaged atmosphere, including sea surface relaxation of temperature and salinity towards climatological monthly means. The models participating in the exercise were those initially used in EU projects MERMAIDS (Pinardi, 1995) and EUROMODEL (Crepón and Martel, 1995). Individual model descriptions can be found

UIB : march, velocity

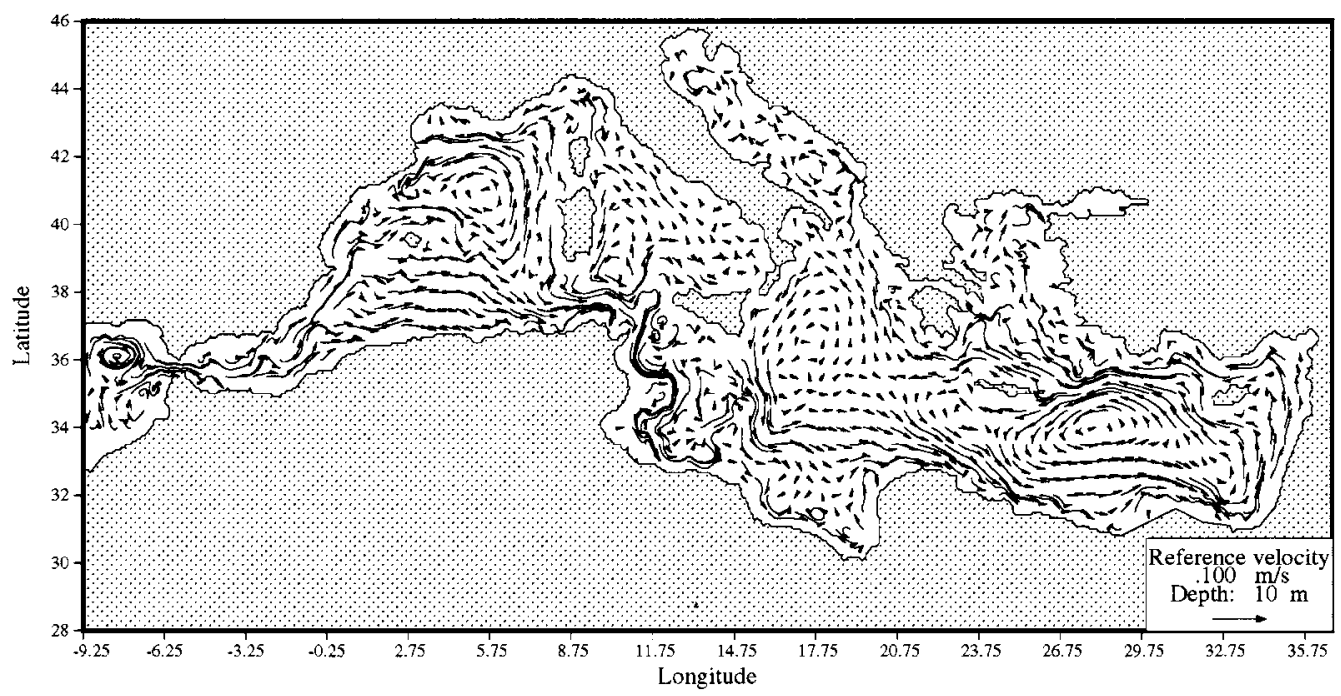

IMGA : march, velocity

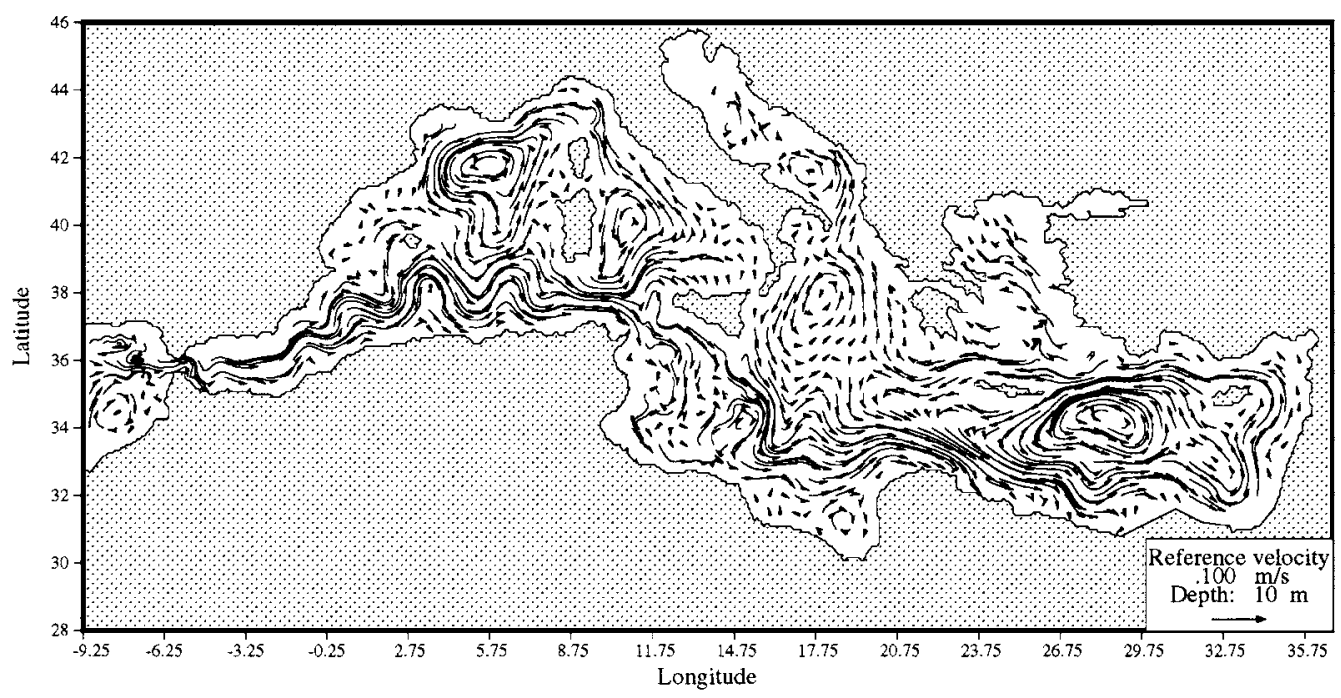

Fig. 4. Velocity fields March Average, experiment I. The vector length in the bottom right inlet corresponds to a velocity of $0.1 \mathrm{~m} / \mathrm{s}$. 


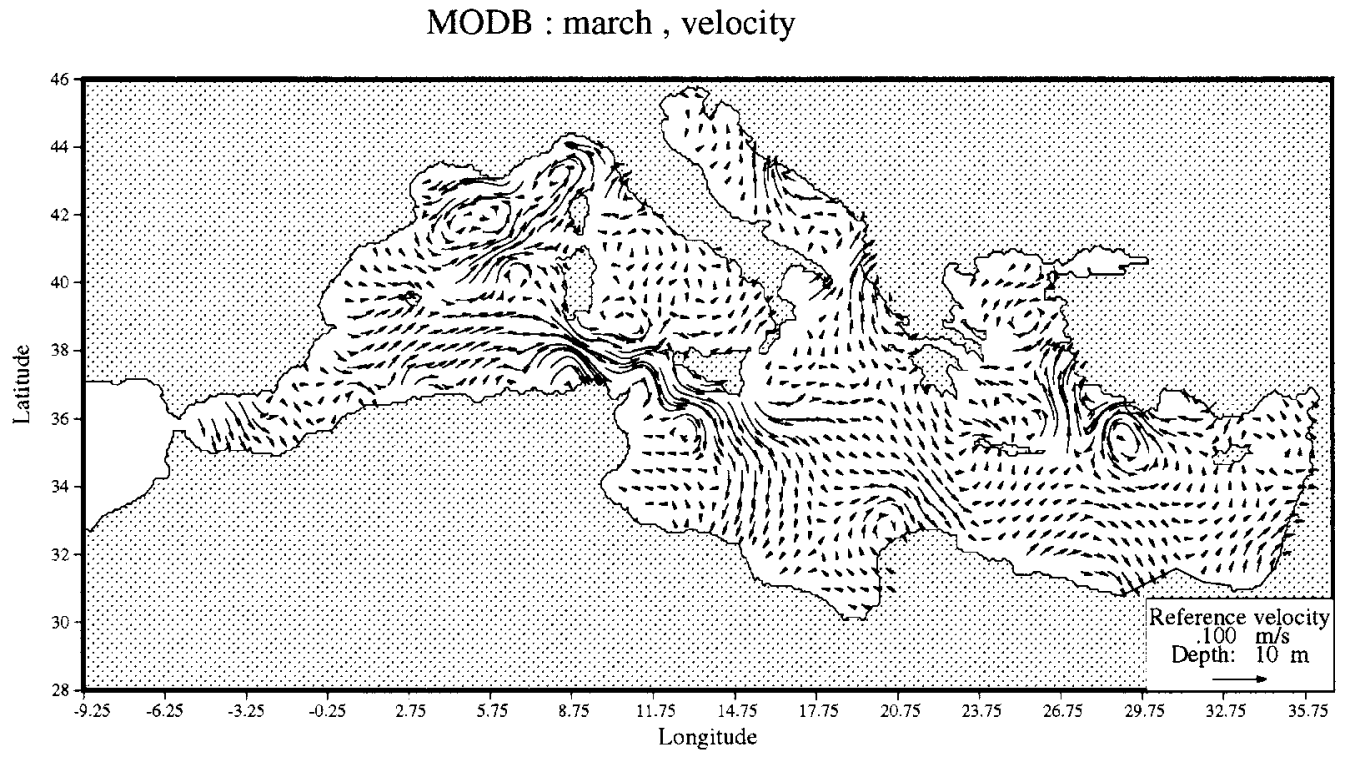

Fig. 4 (continued).

for example in Beckers (1991), Roussenov et al. (1995), Alvarez et al. (1994), Herbaut et al. (1996) and Lascaratos et al. (1993).

Participating models were set up as indicated in Tables 1 and 2 and described in Beckers et al. (1996). Concerning the properties listed in these tables, we can summarise their anticipated effects on simulation results as follows. ${ }^{2}$ For all models, the horizontal numerical grid is either a staggered B-grid or C-grid (Arakawa and Lamb, 1977). Generally, one argues that B-grids behave better at low resolutions and that C-grids behave better at higher resolutions (e.g. Wajsowicz, 1986). C-grid models should also be able to better represent Eulerian advection.

The advection scheme itself is of prime importance for those fields that contain strong gradients. Here, either Leapfrog (centered in time and space) discretisations or TVD schemes are used (Durran, 1999). Leapfrog schemes have the advantage of being easily implemented while conserving tracer concentrations and their variance. However, near frontal structures

\footnotetext{
${ }^{2}$ For a more elaborated discussion of model components, the recent paper of Griffies et al. (2000) can be consulted.
}

their dispersive nature shows up in increased noise levels, needing adequate filtering. TVD schemes on the other hand are relatively expensive to implement, but besides their conservative nature can handle strong gradients.

Since all models use hydrostatic approximation, pressure fields are given by the hydrostatic equilibrium which involves the unknown pressure at a given level or equivalently the sea surface elevation. If the sea surface elevation is retained as a prognostic, time-evoluting variable, external gravity waves are represented in the model and the model is a so-called free surface model. On the other hand, if the surface pressure field is calculated so as to lead to a nondivergent horizontal transport field at each moment, sea surface elevation is a diagnostic variable and pressure calculation involves an elliptic solver (either for directly calculating surface pressure or the stream function from which surface pressure can be diagnosed). In this case the model is a so-called rigid-lid model. Free surface models have the advantage of including an additional physical process that can be easily calculated by a forward integration. Unfortunately, the latter leads to very stringent stability conditions associated with surface gravity waves 


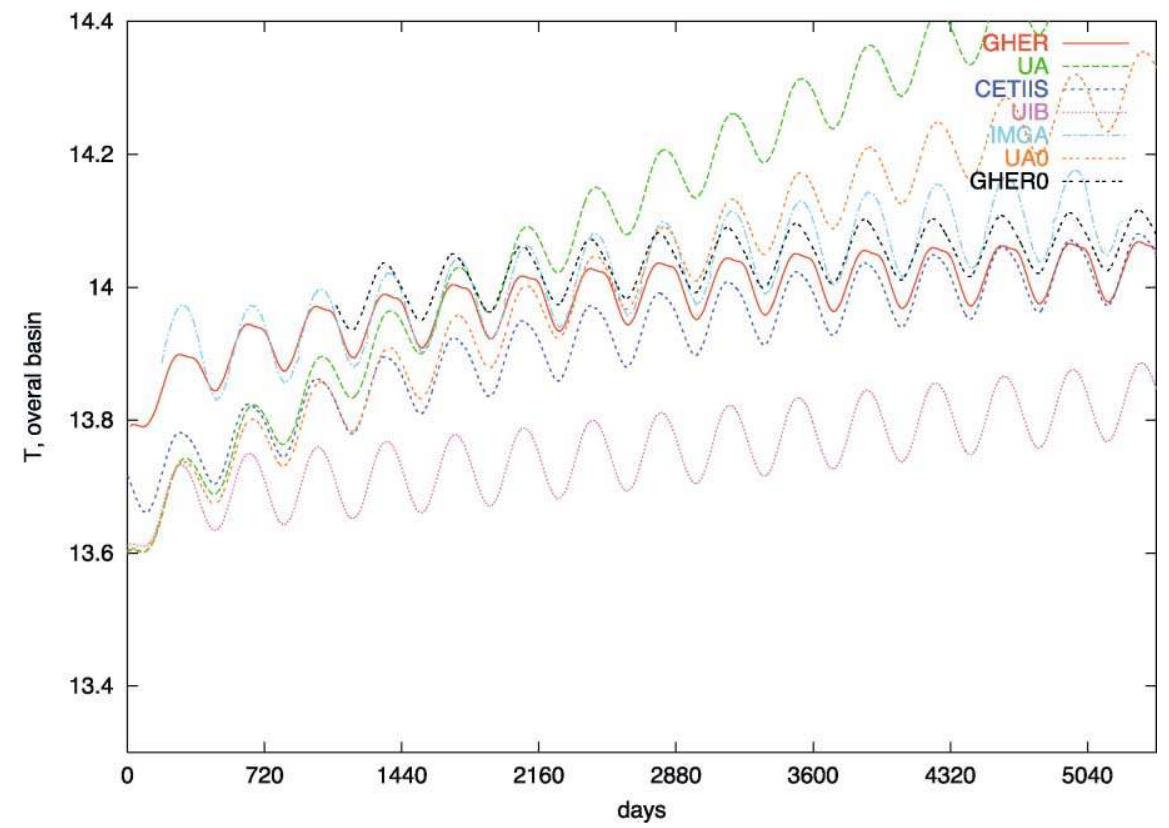

Fig. 5. Average temperature (in degrees celsius), experiment I. GHER0 and UA0 correspond to preliminary simulations with a lower surface relaxation coefficient $(0.5 \mathrm{~m} /$ day $)$.

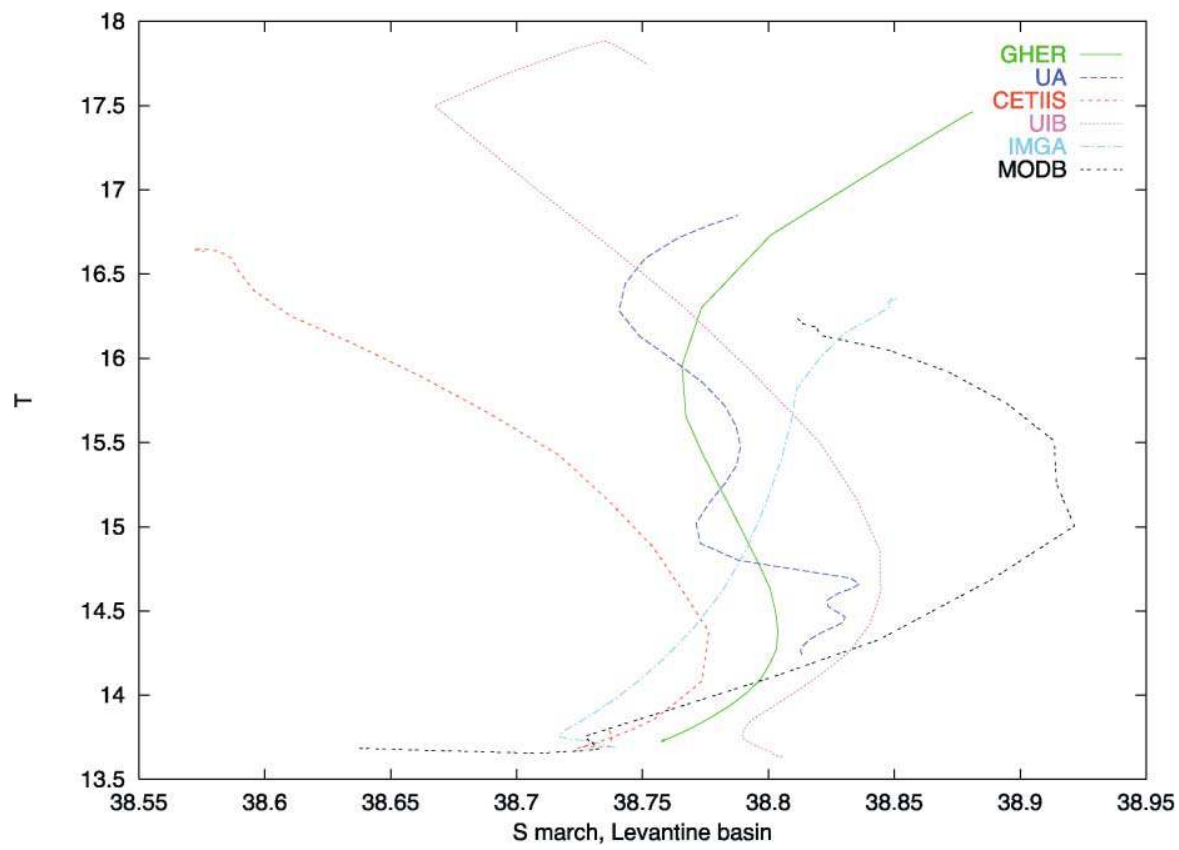

Fig. 6. Average TS diagrams March, Levantine basin $[25 E, 30 E] \times[33 N, 35 N]$. 


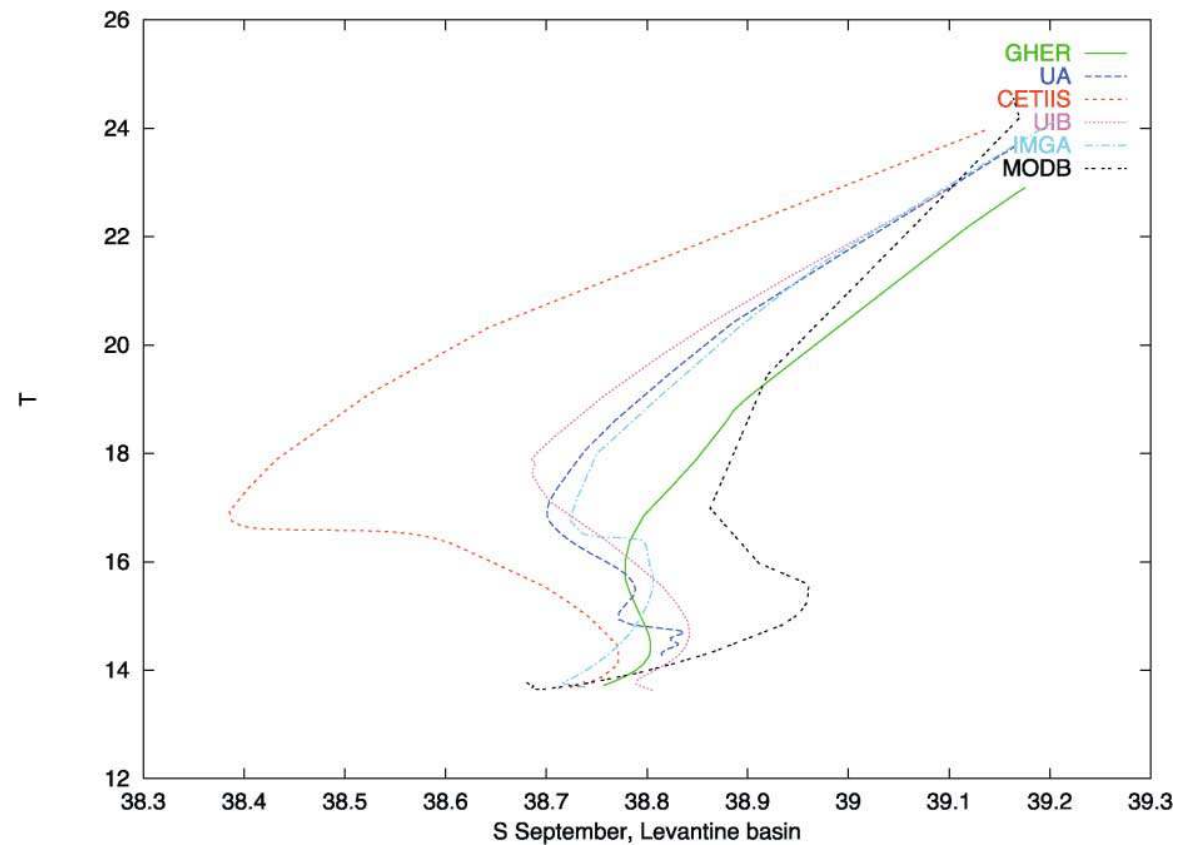

Fig. 7. Average TS diagrams September, Levantine basin $[25 E, 30 E] \times[33 N, 35 N]$.

(Beckers, 1999; Beckers and Deleersnijder, 1993), attenuated by mode-splitting techniques (Killworth et al., 1991). Rigid lid models, on the other hand, can use larger time-steps, but the elliptic solver penalises the model at high resolutions.

The treatment of topography in the models is related both to the horizontal staggering techniques used and the vertical coordinate system retained. In the present case, either terrain-following coordinates or $z$-level models are used. Terrain following coordinates (among which classical $\sigma$-coordinates) allow for correct representation of topographic slopes even without high vertical resolutions, but are hampered by difficulties of representing strong stratifications in the presence of strong topographic variations. For $z-$ coordinate models, the situation is somewhat the inverse. Topographic treatment generally needs some hand-tuning by the modellers, specially in straits, in order to accommodate for the constraints imposed by the numerical discretisations: B-grids need for example more lateral points in a strait than $\mathrm{C}$-grids.

Horizontal diffusion parameterisations in the models are very diverse, partly because lateral diffusion is not only used as a physical parameterisation but also as a numerical filter related to the advection schemes.
On the contrary, vertical diffusion parameterisations are in principle designed to parameterise unresolved mixing processes in the vertical. Parameterisations there range from constant diffusion values to $k-l$ closure schemes, the latter taking into account stratification effects and transport of turbulence.

Tables 1 and 2 show that the vertical and horizontal diffusion parameterisations are very diverse, not only from the functional parameterisation, but also from the values chosen. It should however be noted that some of the model implementations changed their diffusion coefficients after a first comparison of the results with the partners. Values shown here are those retained for the results shown hereafter. Here it can be mentioned that the models with constant vertical diffusion coefficient performed several model runs to calibrate the value of this coefficient, so as to have a closer agreement with MODB data and the average model response.

Models with turbulent closure schemes rather modified the horizontal diffusion parameterisation and coefficient values when carrying out new simulations.

Here it is worth mentioning that the POM model (UA) tried several ways to circumvent the classical 
problem of $\sigma$-coordinate models which diffuse on numerical coordinate surfaces of constant $\sigma$, which causes problems in regions where strong stratifications meet strong topographic gradients. Subtracting mean vertical temperature and salinity profiles before diffusing, reducing the Smagorinsky coefficients, etc., did not correct for a stronger drift in the subbasins observed in the POM implementation compared to the other models. Recently, the stronger drift was shown to result indeed from the horizontal diffusion part, and a modified rotated diffusion (Nittis and Lascaratos, 1999) has put the UA results more in line with the other models subbasin drifts.

Figs. 1-4 represent horizontal distributions for salinity and velocity fields during an averaged March situation for the different models after the 15 years of

GHLR : march, Salinity field

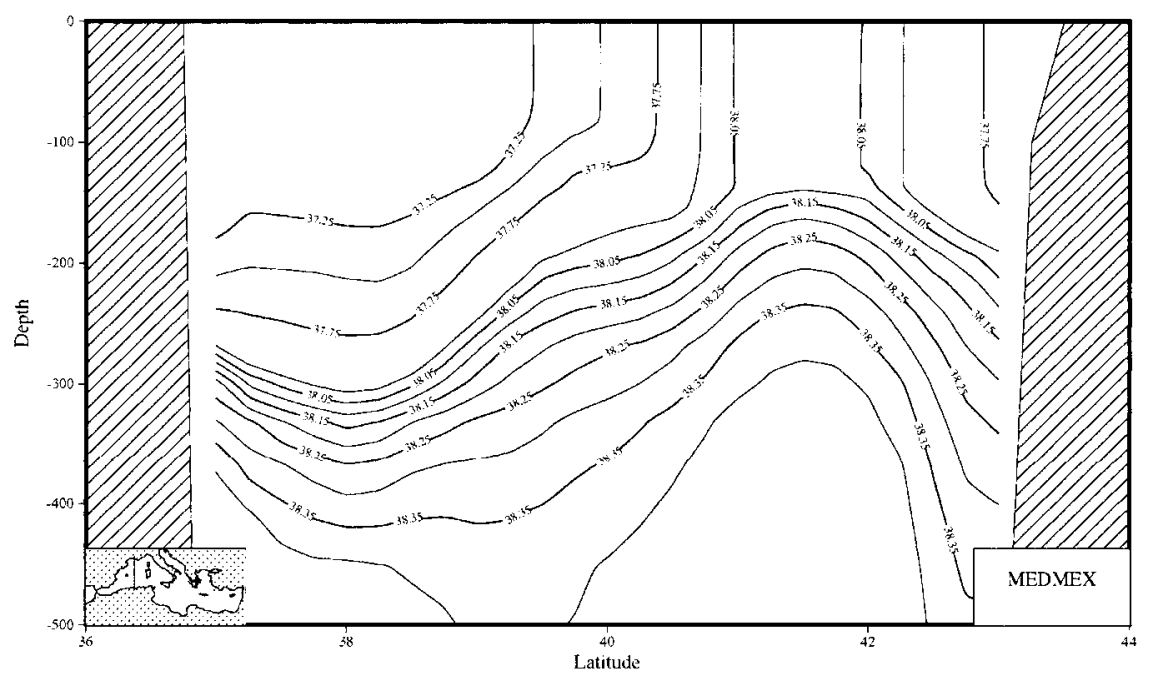

UA : march, Salinity field

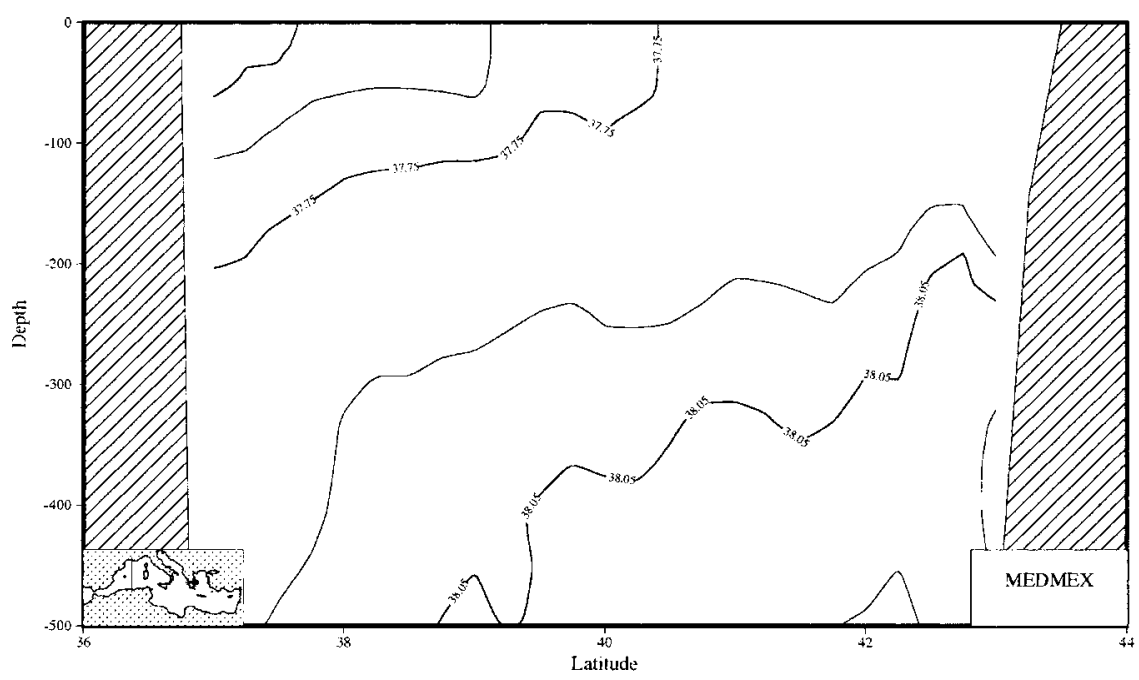

Fig. 8. Salinity section across the Gulf of Lions. March average, experiment I. 


\section{CETIIS : march, Salinity field}

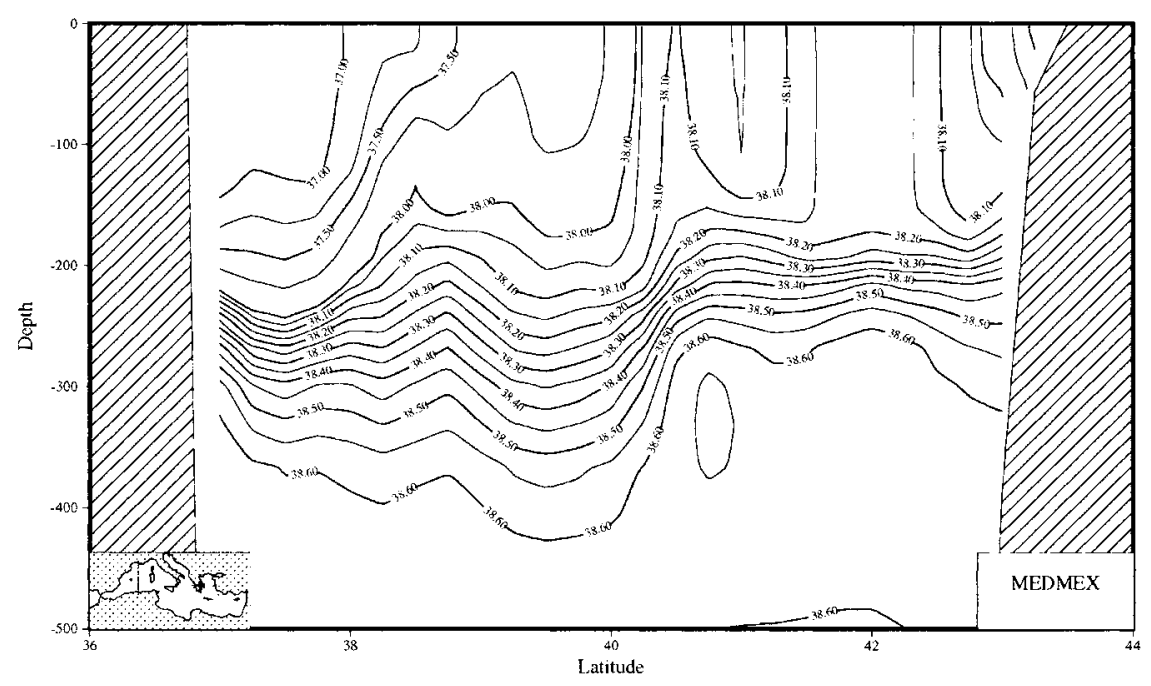

Fig. 8 (continued).

repeated forcing. All models reproduce the major large scale features of the Mediterranean surface circulation: inflow of Atlantic waters from Gibraltar, its eastward propagation into the Levantine basin and the cyclonic backward flow. All models show a flow separation in the Sicily strait, one branch along Tunisia, the other along the southwestern Sicily coast. Even if surface temperature and salinity fields are relaxed towards climatology (MODB data in Fig. 2) and thus reflect the sea surface climatological fields, it can clearly be observed that the models allow for coastal currents with different characteristics than the smoothed MODB fields. This is because the relaxation is weak and the models develop their own dynamics including the jetlike structures absent from climatological surface data. Except for the UIB model with a higher horizontal diffusion for salinity, the other models create a dynamical variability, specially in the inflow region and the eastern basin. Circulation is similar in all models and much stronger than the purely geostrophic flow associated with MODB hydrography. Furthermore, the small scale perturbations in the UA simulation seen on the salinity fields also are reflected in the current fields. The models thus represent the circulation pattern during winter in a similar way. Though not shown here, surface fields during the other seasons behave similarly, with decreased current intensity in summer. Also, specially in the CETIIS and GHER models, the Atlantic water inflow detaches from the African coast in summer. A weaker signal of this seasonal variation is found in the UIB, UA and IMGA models. Smallerscale features are different in the models and the Alboran gyres are not always present. The GHER model also shows too strong a detachment of the Algerian current with a recirculation along the African coast in winter.

Model differences in the circulation patterns are only visible in the secondary circulations, typically for the anticyclonic gyres between the main current jets and the coasts (Algerian currents, Mersa-Matruh gyre, etc.). The strength of these gyres was controlled mainly by the horizontal diffusion (as shown by additional experiments with changed lateral diffusion).

Even if surface patterns are coherent with the general description of the Mediterranean circulation, discrepancies exist. Due to the monthly averaged forcing functions and a relatively weak surface relaxation, all models have difficulties to produce the correct water masses in this simulation, which is easily revealed by looking at the average temperature of the model results during the 15 years. As seen on Fig. 5, temperature increases in the models (with a superimposed seasonal cycle) due to insufficient cool- 
ing and vertical mixing in winter. It is worth noting that the models with constant vertical diffusion exhibit the stronger drifts and that a change in the relaxation coefficient (compare UA with UA0 and GHER with GHER0) does lead to changes in the drifts, but these changes are smaller than the differences in drifts between the models. A temperature drift is observed in all models, on which the annual cycle is super- imposed. If we denote by $\bar{T}$ the annual average and by \langle\rangle the spatial average, we have the following relationship describing the time-evolution of the mean temperature in the basin:

$\rho C_{\mathrm{p}} V \frac{\mathrm{d}\langle T\rangle}{\mathrm{d} t}=-S\langle Q\rangle$

where $V$ is the volume of the basin and $S$ its surface.

UIB : march , Salinity field

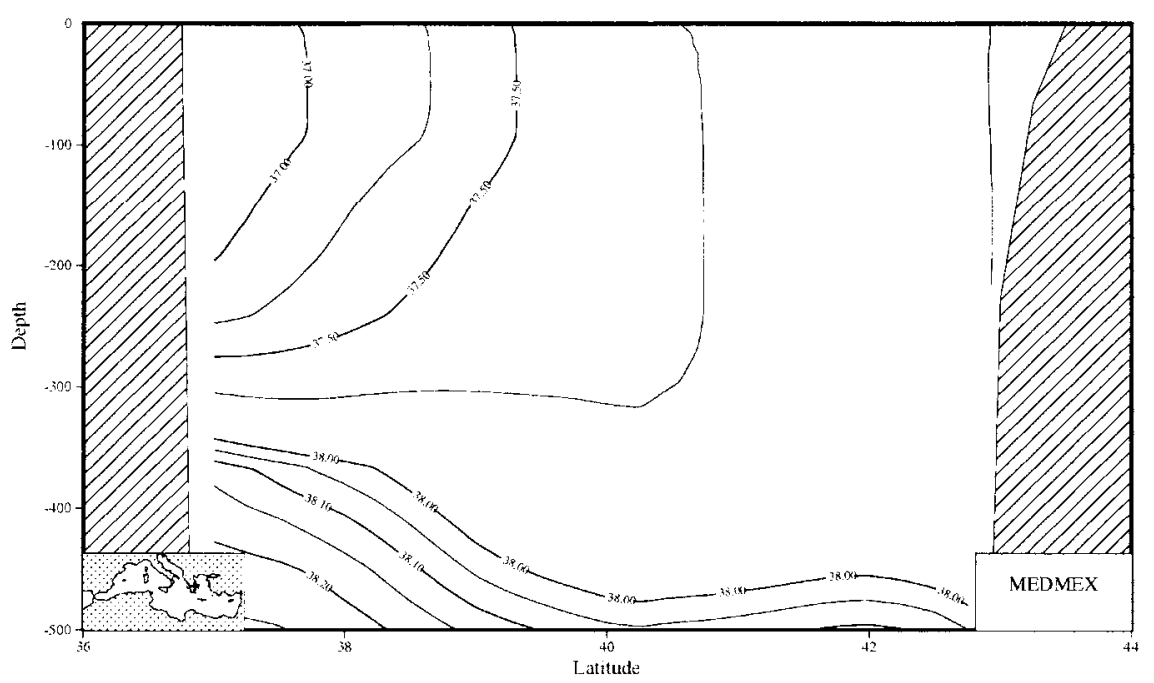

IMGA : march , Salinity ficld

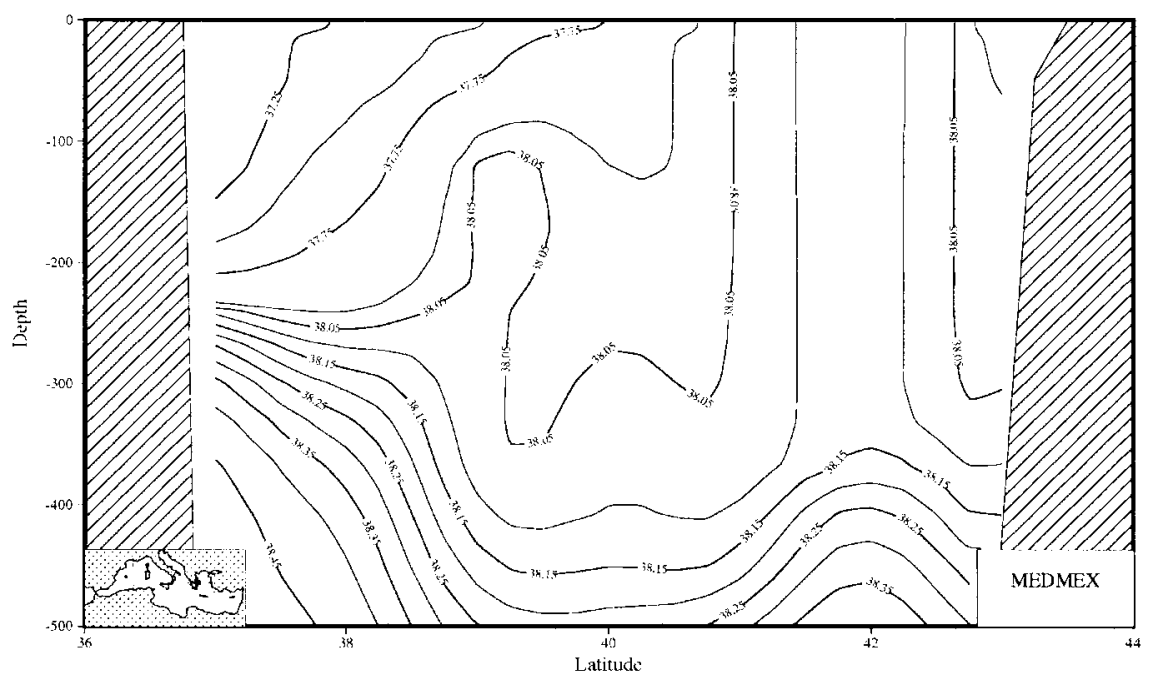

Fig. 9. Salinity section across the Gulf of Lions. March average, experiment I. 
MODB : march , Salinity field

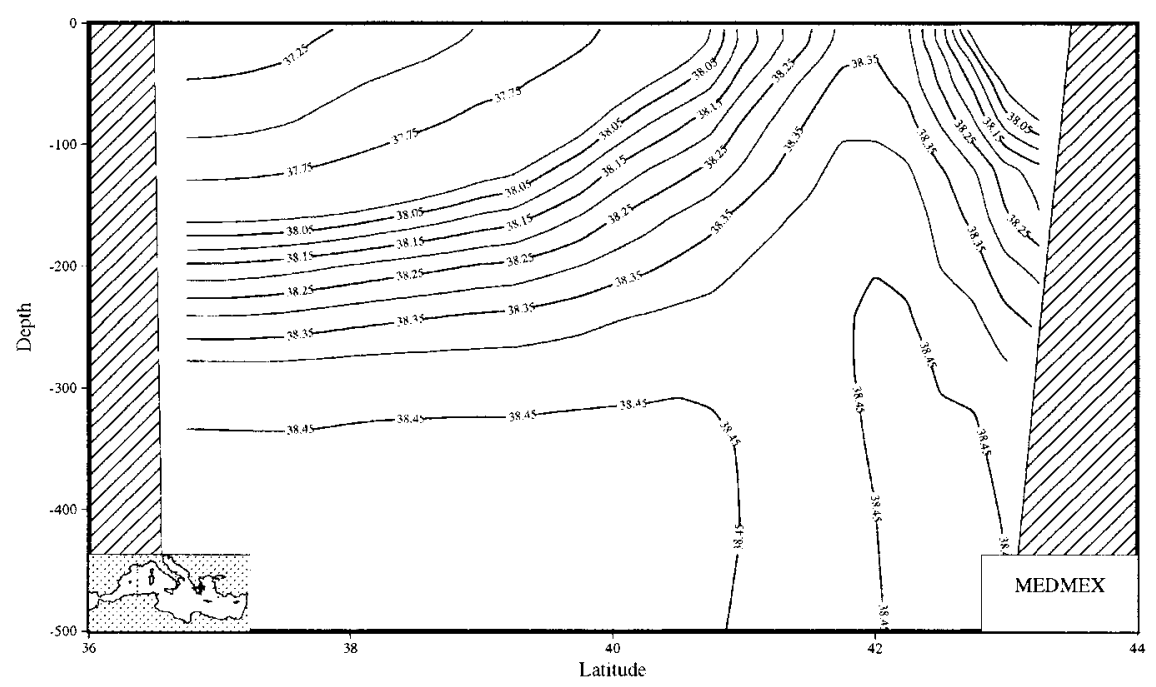

Fig. 9 (continued).

In a first approximation $\langle T\rangle=\langle\overline{\mathrm{T}}\rangle-A_{T} \sin \omega t$, $\omega=2 \pi$ year $^{-1}$, so that

$$
\langle Q\rangle=A_{T} \omega \rho C_{\mathrm{p}} V / S \cos \omega t
$$

When using the amplitude of the seasonal mean temperature evolution in Fig. $5, A_{T}=0.05{ }^{\circ} \mathrm{C}$, we recover a heat flux whose seasonal amplitude is 68 $\mathrm{W} \mathrm{m}^{-2}$. For the drift induced by an annual heat budget which is not closed, the nonequilibrium value gives a drift of

$\rho C_{\mathrm{p}} V \frac{\mathrm{d} \overline{\langle T\rangle}}{\mathrm{d} t}=-S \overline{\langle Q\rangle}+S \overline{Q_{\mathrm{Gib}}}$

At Gibraltar the theoretical equivalent annual heat input is about $7 \mathrm{~W} \mathrm{~m}^{-2}$. The models, rather than losing these $7 \mathrm{~W} \mathrm{~m}^{-2}$ at the surface, still heat the system by a few $\mathrm{W} \mathrm{m}^{-2}$, so the a drift of about 0.05 is observed for a budget heat deficiency of $10 \mathrm{~W}$ $\mathrm{m}^{-2}$. Concerning the annual cycle, it is clear that the amplitudes of the heat fluxes variations are too low, since atmospheric data analysis shows amplitudes of $150 \mathrm{~W} \mathrm{~m}^{-2}$.

An analysis of the subbasins shows that some models have specific drifts in particular subbasins. Figs. 6 and 7 show for example the TS characteristics of the models in the Levantine basin in March and
September. After the summer, each model exhibits the typical " $\mathrm{S}$ " shaped $\mathrm{T}-\mathrm{S}$ diagram also found in the MODB climatology, with a sub-surface salinity minimum, but the curves are shifted compared to the MODB data, typical of a model drift. During winter, no model is able to produce the high salinity Levantine intermediate waters correctly, generally producing them too cold and not salty enough.

Vertical sections across the Gulf of Lions confirm the difficulties of the models to create the deeper waters when using monthly relaxation. Figs. 8 and 9 show the different model representations of the doming during March (as a reference, the MODB climatological data) and the deep water characteristics and their drifts. The doming associated with the northern gyre is most clearly visible in IMGA and GHER models, which could explain why in the UA model, even the Mellor-Yamada scheme (which should help in mixing during deep water formations) cannot convect deep enough because of the absence of preconditioning. A typical indication for model drifts is the fact that positions of salinity gradients are comparable, while the salinity values are different by as much as 0.5 around $500 \mathrm{~m}$. The weak surface relaxation used in this experiment is partly responsible for the drifts; as shown by an experiment with a very strong surface relaxation during the deep water formation 
phases, it is possible to form the necessary deep waters (Myers and Keith, 2000).

The large salinity differences in the subsurface layers are also visible in Figs. 10 and 11, where the freshening in the UA and UIB model in the western basin is particularly striking. In accordance with the analysis of the vertical sections in the Gulf of Lions, the absence of the doming and a downward mixing of fresh waters seems responsible for these larger drifts. It is also worth noting that the IMGA model (and to some extent the GHER model) is the only one with higher salinities at the African coast than in the interior of the western basin, showing the preferred path of LIW in this model.
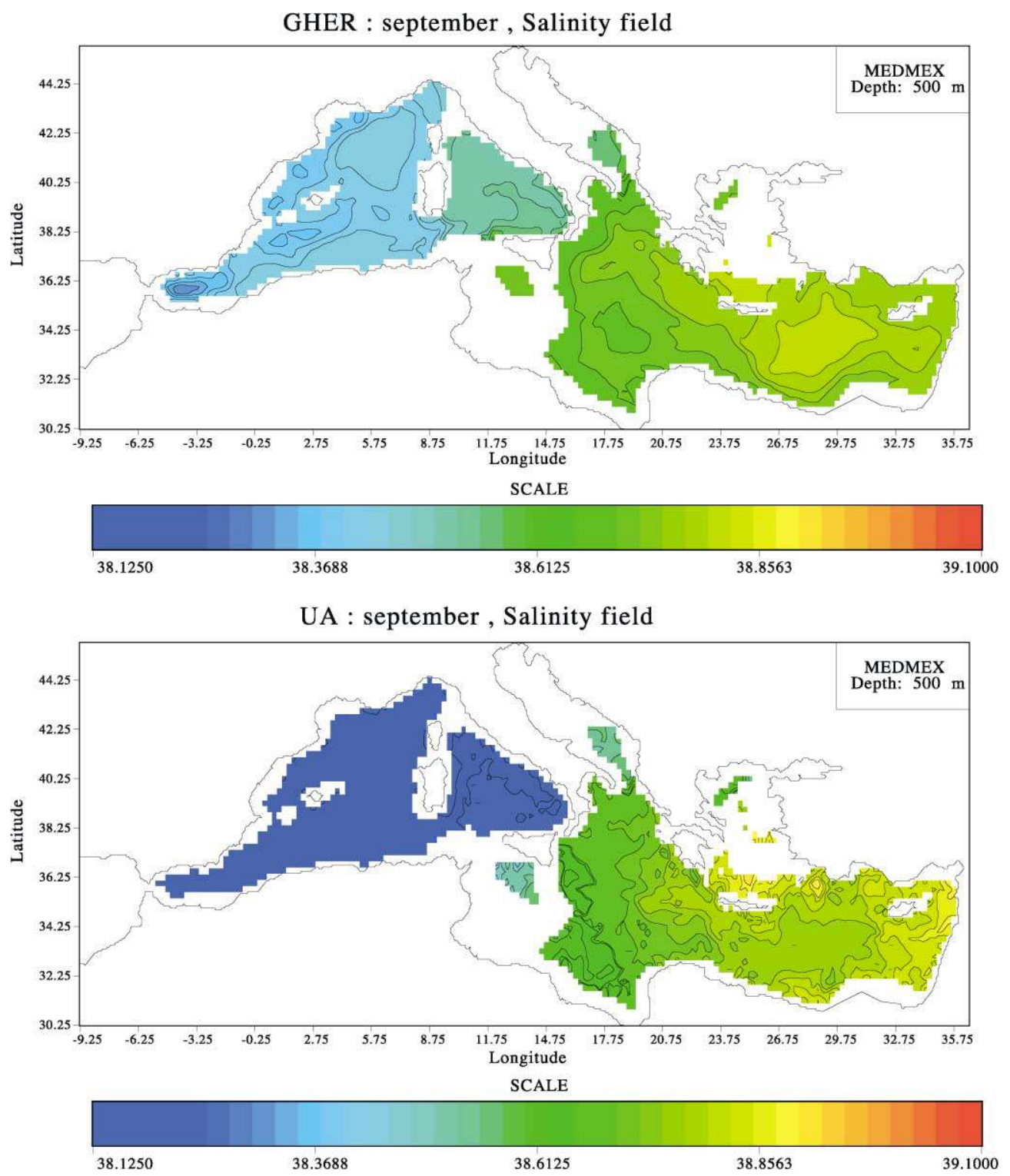

Fig. 10. Salinity fields September average at 500-m depth, experiment I. 


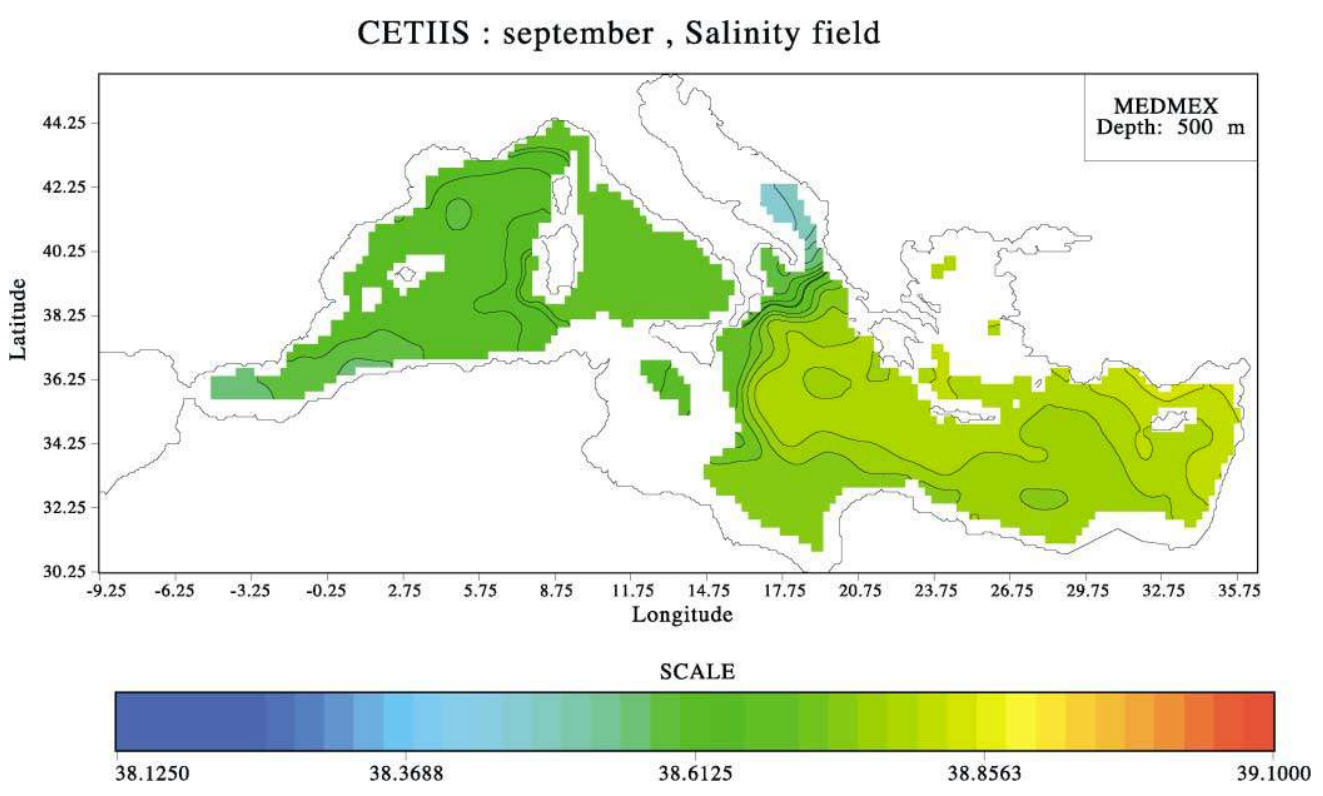

Fig. 10 (continued).

Model differences can also be analysed by looking at the energy level in each of them. This can be illustrated by looking at the values of the volume $V$ averaged squared velocity $1 / V \int_{V}\left(u^{2}+v^{2}\right) \mathrm{d} V$ representative of the kinetic energy (the volume average ensures that the effect of using different topographies in the models is not emphasised). Since in experiment I, we look at monthly averaged forcings, we can directly compare the energy associated with the monthly averaged velocity fields. This is done in Table 3. Though each model clearly is able to represent the kinetic energy decrease by around 30\% during the summer season, the total energy of each model is quite different. Since both the CETIIS and IMGA models work with similar horizontal friction, the constant vertical diffusion of $10 \mathrm{~cm}^{2} / \mathrm{s}$ of the IMGA model is likely to be the reason for the lower energy in the IMGA model. This is confirmed by the fact that a previous run (UIB0) with the MOM model having a 10-fold higher lateral diffusion but a 10 -fold lower vertical viscosity had led to an energy three times higher. Models with turbulent closure schemes consistently show the highest energy and least dissipation.

Model differences have been found to be mainly due to the vertical diffusion in the models. The addition of a chemical tracer in the models (Roether et al., 1998) would certainly have been useful in order to study this effect without the feedback of the tracer diffusion onto the circulation.

The fact that the vertical diffusion seems to be major control parameter of the model's results can be confirmed by a scale analysis. Indeed, if we compare the vertical diffusion to the vertical advection (both responsible for the changes in the internal pressure gradient changes through density $\rho$ ) we find the following estimations:

$w \frac{\partial \rho}{\partial z} \sim \frac{W \delta \rho}{H}$

where $W$ is a typical vertical velocity and $H$ a typical vertical scale for changes in water mass properties. Similarly, vertical diffusion due to the diffusion coefficient $v$ scales like

$\tilde{v} \frac{\partial^{2} \rho}{\partial z^{2}} \sim \frac{\tilde{v} \delta \rho}{H^{2}}$

Since we are working at large scales, vertical velocity is related to the horizontal velocity scales $U$ and horizontal length scales $L$ by a quasi-geostrophic 
scaling, i.e. $W / L \sim R o(U / L)$ where $R o$ is the Rossby number, much smaller than unity in our case. Therefore, the ratio $r$ of diffusion to vertical advection scales like

$r \sim \tilde{v} \frac{L}{R o \times U H^{2}}$
In the Mediterranean we have $L \sim 10^{5} \mathrm{~m}, R o \sim$ $0.01-0.1, H \sim 10^{2} \mathrm{~m}, U \sim 0.1 \mathrm{~m} / \mathrm{s}$, and thus

$r \sim\left(10^{3}-10^{4}\right) \tilde{v}$

where $\tilde{v}$ is in $\mathrm{m}^{2} / \mathrm{s}$. For the typical interior value of $10^{-4} \mathrm{~m}^{2} / \mathrm{s}$, advection and diffusion are of the same

UIB : september, Salinity field

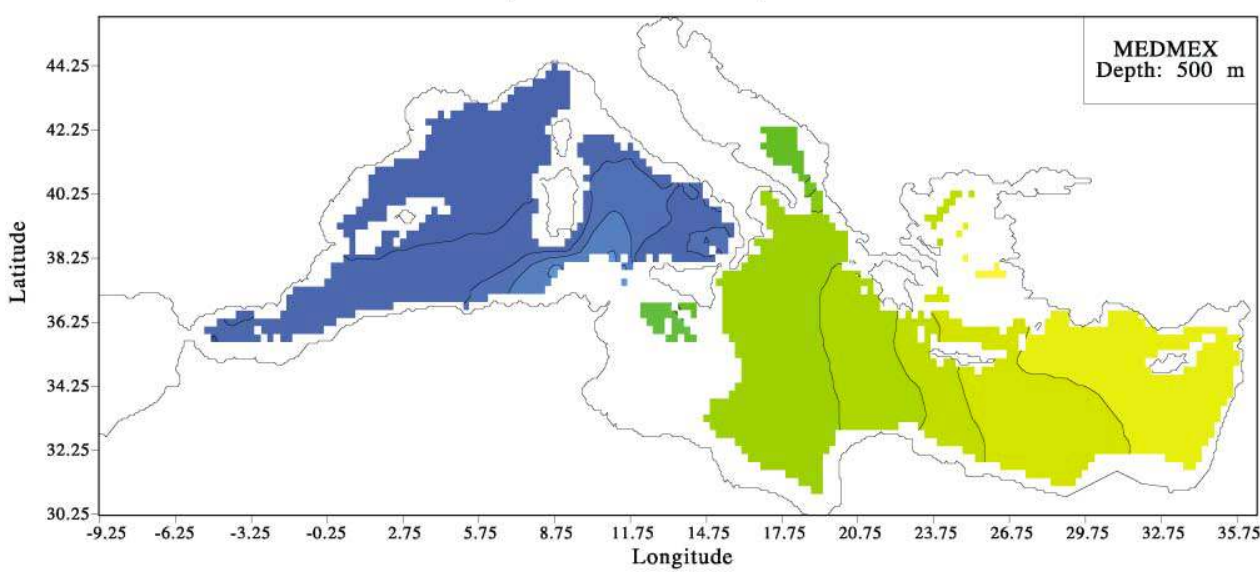

SCALE

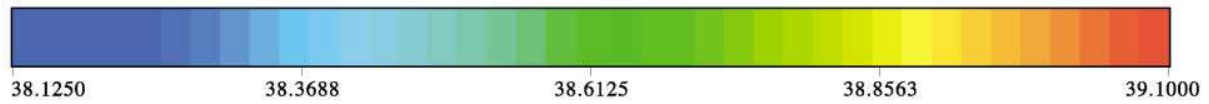

IMGA : september, Salinity field

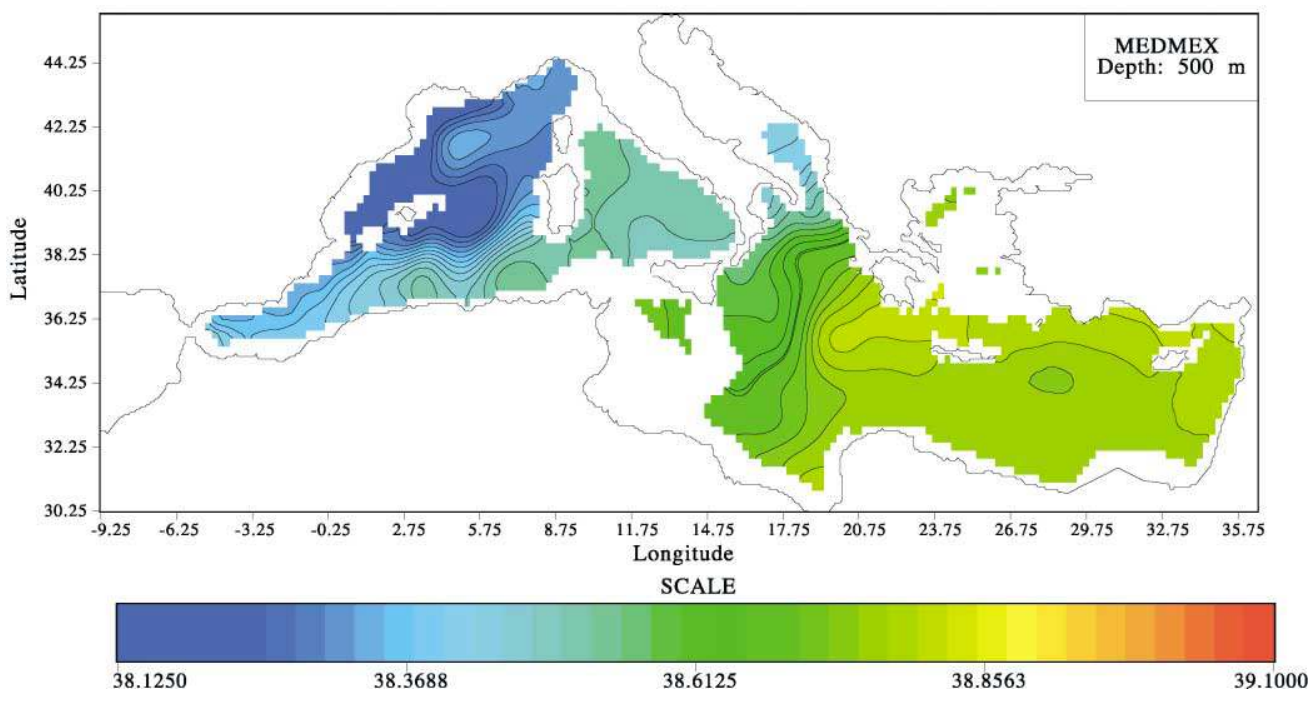

Fig. 11. Salinity fields September average at 500-m depth, experiment I. 


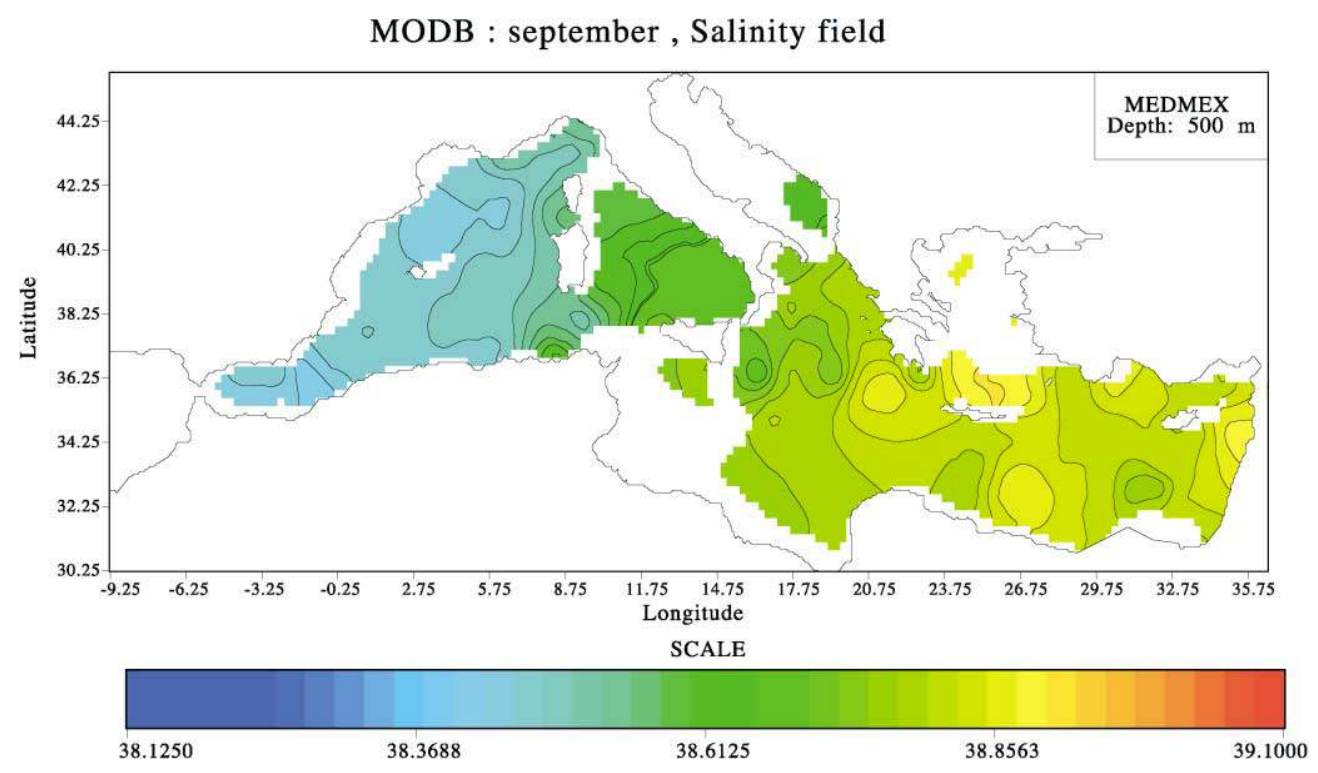

Fig. 11 (continued).

order of magnitude, while in proximity of the mixed layer diffusion dominates as one could expect. In any case, vertical diffusion plays a crucial role in the redistribution of density and therefore its parameterisation must be done carefully.

\section{General circulation simulated by daily atmospheric forcing, experiment II}

In order to verify if the averaged forcing was responsible for the drift and also to identify how the models behave when shorter time scales are present, a daily forcing was then applied. The setup of the models was exactly the same as in the previous coarse resolution experiment. Only sea surface forcing was changed from monthly averaged values to daily forcings starting in 1978 for 15 years, using ECMWF reanalysed wind-stress fields, heat fluxes, evaporation due to latent heat fluxes and climatological Jaeger

Table 3

Average kinetic energy measure (in $\mathrm{cm}^{2}$ ) for the different models

\begin{tabular}{llllll}
\hline & GHER & UA & CETIIS & UIB & IMGA \\
\hline March & 12.01 & 8.03 & 2.64 & 2.11 & 1.5 \\
August & 10.31 & 6.44 & 2.10 & 1.48 & 1.1 \\
\hline
\end{tabular}

precipitations. For salinity, an additional weaker relaxation towards climatological sea surface salinity was maintained, due to the relatively large errors in precipitation fields. For practical reasons, not all models participated in this exercise (called experiment II) and only GHER, UA, CETIIS and IMGA results are therefore presented.

In comparison, model results (averaged over 5 days) of surface temperature in March of the last simulation year (Figs. 12 and 13) now show much larger differences between the models, due to the absence of relaxation and the different vertical exchanges in the models. All models clearly represent the cooling in the northern Aegean. The cooling in the Gulf of Lions is also present in the models (except for the UA model). The northern Adriatic cooling is partly cut away by the topographic treatment in the IMGA model, while the CETIIS model keeps too high a temperature there. All models maintain a temperature difference between the eastern and western basin.

The strong northwestern winds in the Ionian basin observed during the winter months clearly lead to Eekman drifts to the south in all models (Figs. 14 and 15). Since the model resolutions are different and the vertical mixing parameterised differently, it is not surprising that the Eekman drift is not identically 
resolved. On the other hand, the general flow patterns from the western basin along the Algerian coast to the mid-ionian jet and the cyclonic circulation in the far east and the north-western basin are clearly reproduced by all models. Circulation patterns constitute thus a relatively stable feature of all models, contrary to the vertical density structure. Since the circulation pattern is forced by both the wind-stress fields and baroclinic pressure gradients, we can interpret this as follows: near the surface, wind-stress is forcing the models in an identical way; the surface density structure is directly influenced by the atmospheric forcing, which is identical in all models, so that the baroclinic structure near the surface is similar. Therefore, the surface circulation patterns are stable features of the models. That the circulation patterns in deeper

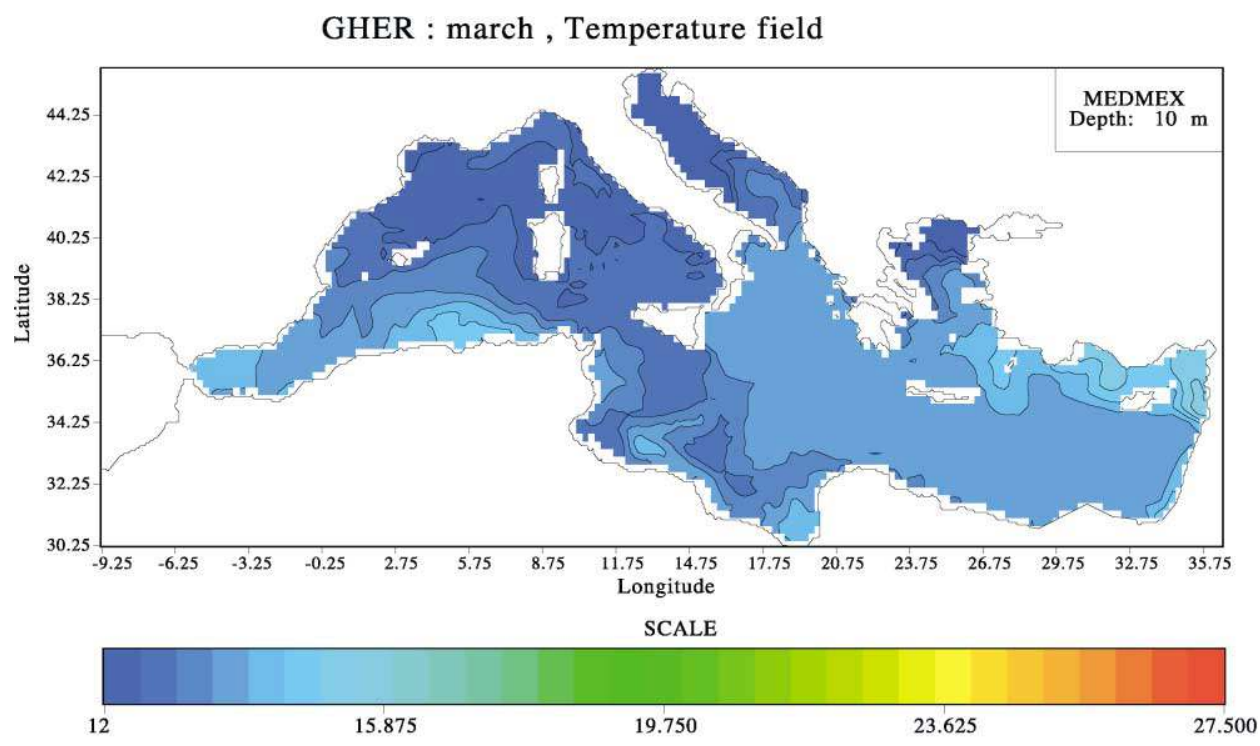

UA : march , Temperature field

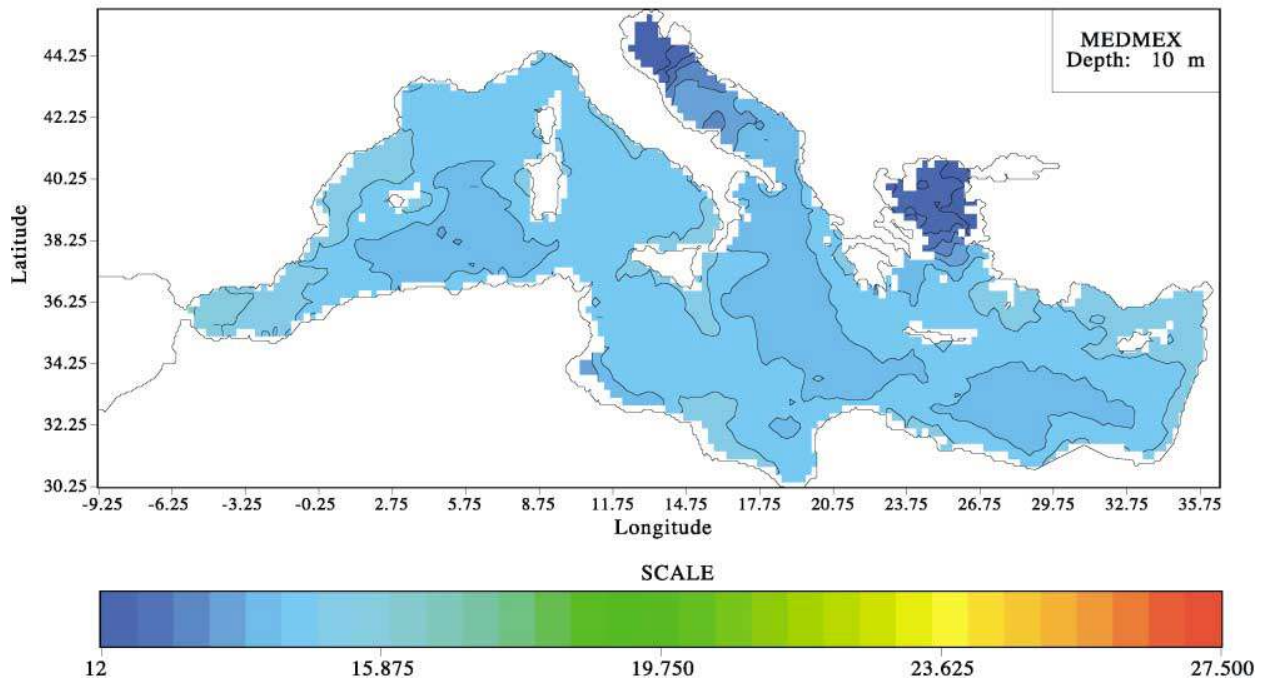

Fig. 12. Temperature fields March average, experiment II. 


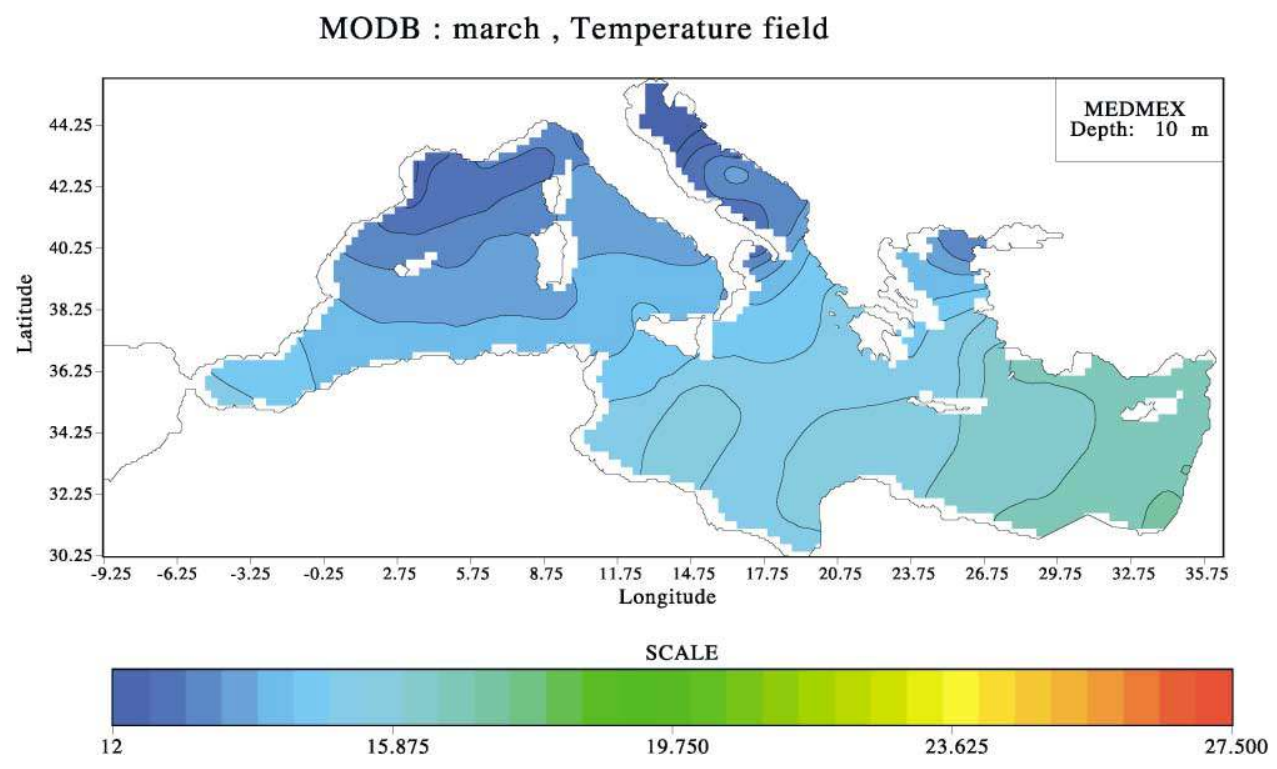

Fig. 12 (continued).

regions also are similar is more of a surprise, since the density fields of the models are quite different. Having similar flow fields therefore indicates that the models do not differ so much in terms of baroclinic pressure, but rather in subbasin average stratifications. In other words, the global drifts in the models are quite different. This is also supported by the analysis of average temperatures (at basin scale as shown in Fig. 16 or at subbasin scales not shown here). Indeed, the model seasonal cycle amplitudes are similar, but the drifts rather different (be it in experiment I or II). Since in experiment II the heat flux is imposed, average temperature differences at basin scale can only be due to differences in exchanges at the Gibraltar Strait, showing how sensitively the model drifts react. This is also confirmed by a second experiment (GHER2) where a weak relaxation towards MODB surface temperature was added, with typical changes in the fluxes of less than a few watts per square meter.

Not only do the average temperatures of the models differ, but also the vertical distribution. Compared to experiment I, the doming in the Gulf of Lions is now better represented in the models. They still exhibit rather large differences in the deep water mass structure there (Figs. 17 and 18), which is confirmed by the average temperature evolution in the models.
(Fig. 16). Propagation of the density information in the models from the surface to the deeper waters needs very special attention, at least as much as the surface forcing itself.

In order to help analyse the model results and compare the models excluding the effect of the different vertical mixing and drifts, an EOF analysis on the last 10 years of integration on the 10-day averaged sea surface temperature fields was performed. It should be noted that SST evolutions from the CETIIS simulation were not made available and therefore EOF calculations were not performed for CETIIS. Sea surface temperature is understood as being the temperature in the upper level of calculation in each model, coherently with the assumption used in each model that the upper level is representative of the sea surface temperature excluding skin temperature. Variances explained by the corresponding EOF are given in Table 4 and show that the first mode explains almost the complete variance.

Analysis of the temporal evolution of the amplitude of the EOF (Fig. 19) clearly shows the seasonal character of this signal, which also justifies a posteriori our first experiment.

The spatial structure of this seasonal EOF is strikingly similar for all models and the climatological 

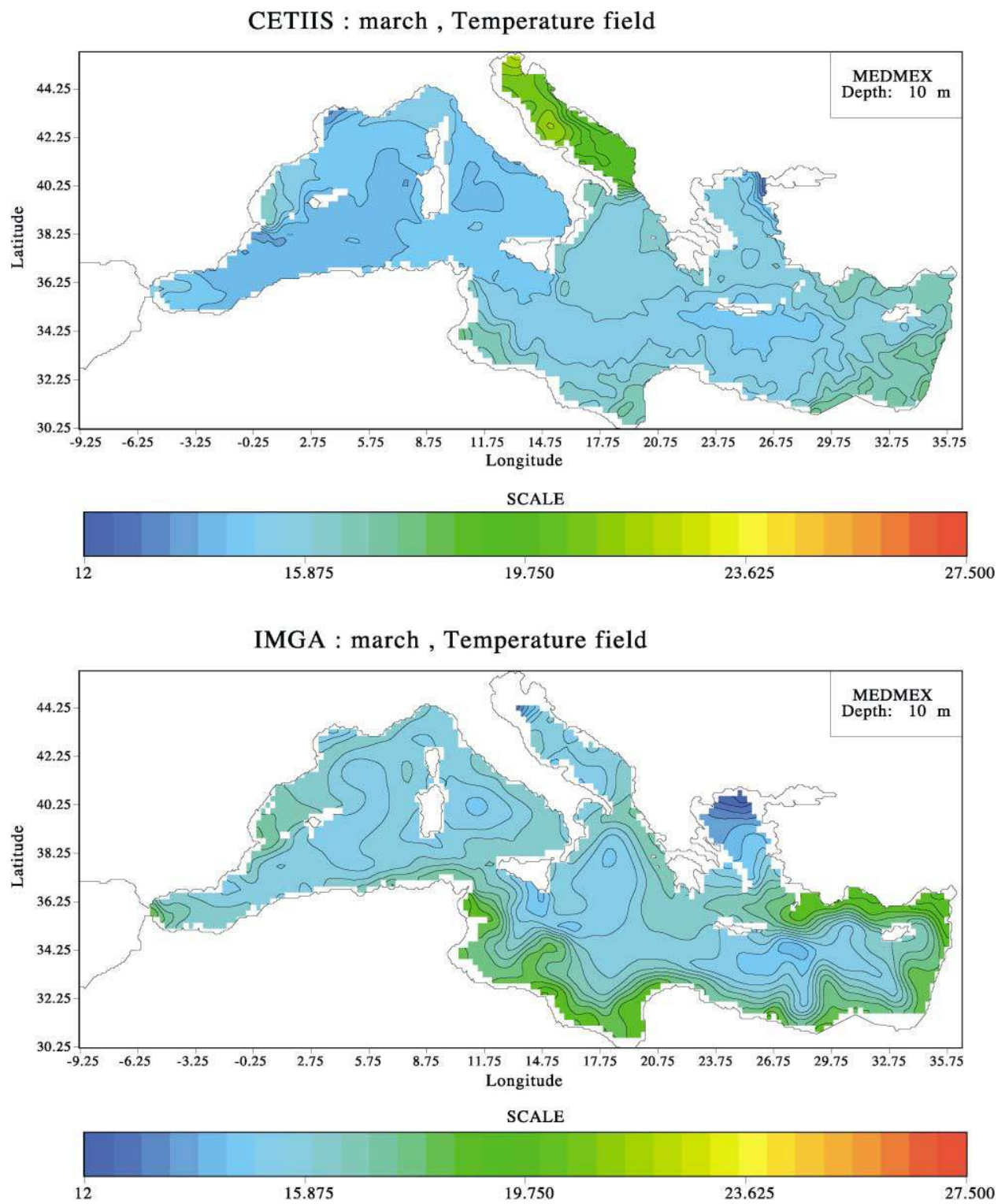

Fig. 13. Temperature fields March average, experiment II.

data (Figs. 20 and 21), even for such details as the local upwellings at the Sicilian coast in the Sicily strait or the strong gradient of variability between the eastern and western Aegean. However, amplitudes are quite different and the maximums shifted slightly in time. This shows the interest in comparing EOF's, since direct comparison at a given moment could overemphasise model differences. Here the EOF decomposition shows how the models represent the dominant cycle in a very concise way. The EOF decomposition also shows that the regions with the weakest seasonal cycle in the surface temperature are the Gulf of Lions, the northern Aegean and the Alboran Sea.

Finally, in order to find another way of comparing models having different average mixing processes, the 
GHER : march, velocity

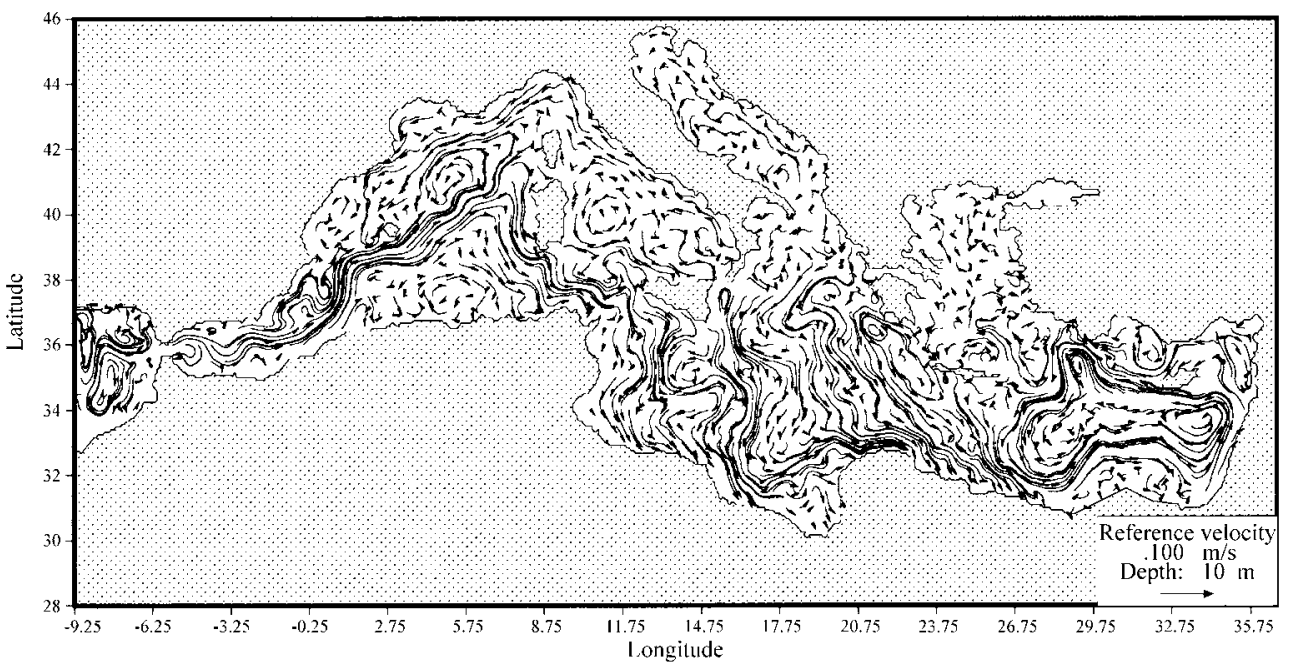

UA : march, velocity

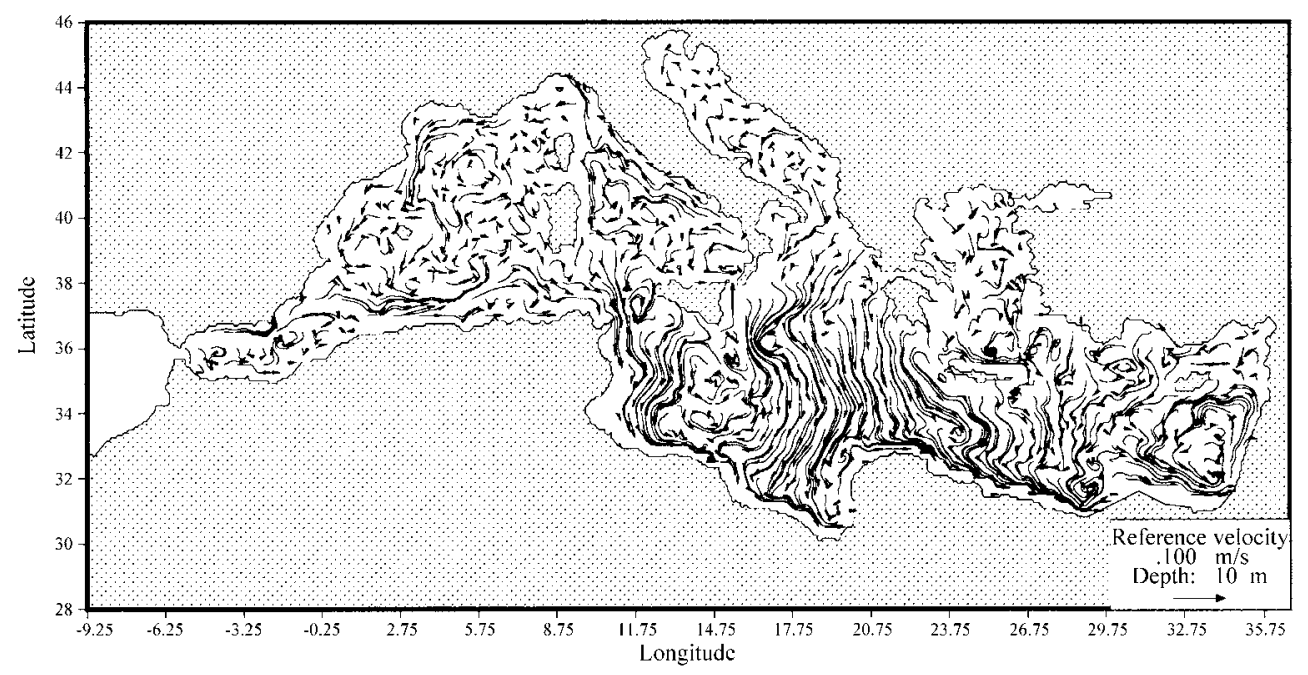

Fig. 14. Velocity fields March Average, experiment II.

models can also can be compared on isopycnals (Figs. 22 and 23).

All models clearly show the very different water masses found in the western basin compared to the Rhodes region because of their very different salinities on the isopycnal. The Atlantic waters can clearly be distinguished from those of the Levantine basin. Here we can notice that even if the MODBISO analysis was performed directly in the isopycnal space (increasing the signal to noise ratio of the data and therefore the sharpness of the analysis), the climatological data smear out the flow of Atlantic waters into the Levantine basin. On the contrary, the models maintain strong gradients of salinity on the isopycnal, corresponding to the position of the separation between the water masses. Moreover, we also can notice that the choice of isopycnals for comparison eliminates part of the drift effects and that on isopycnals, structures are 


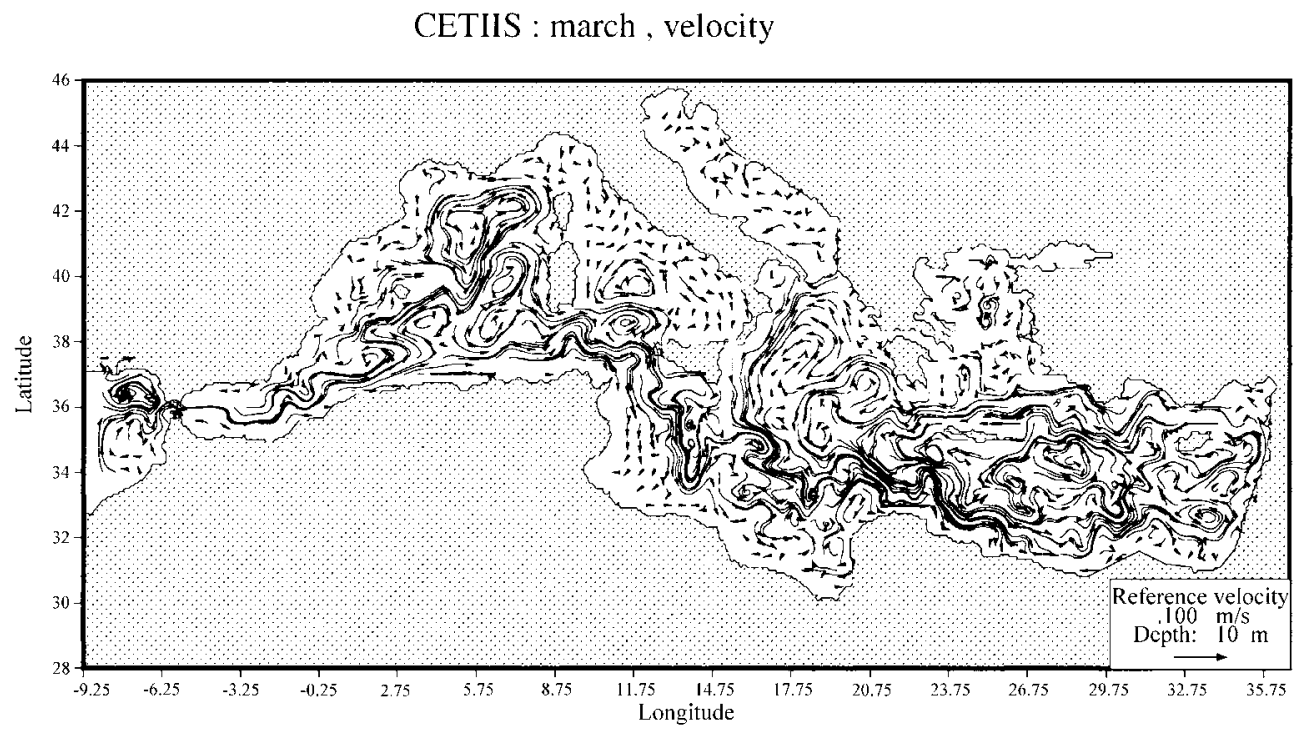

IMGA : march, velocity

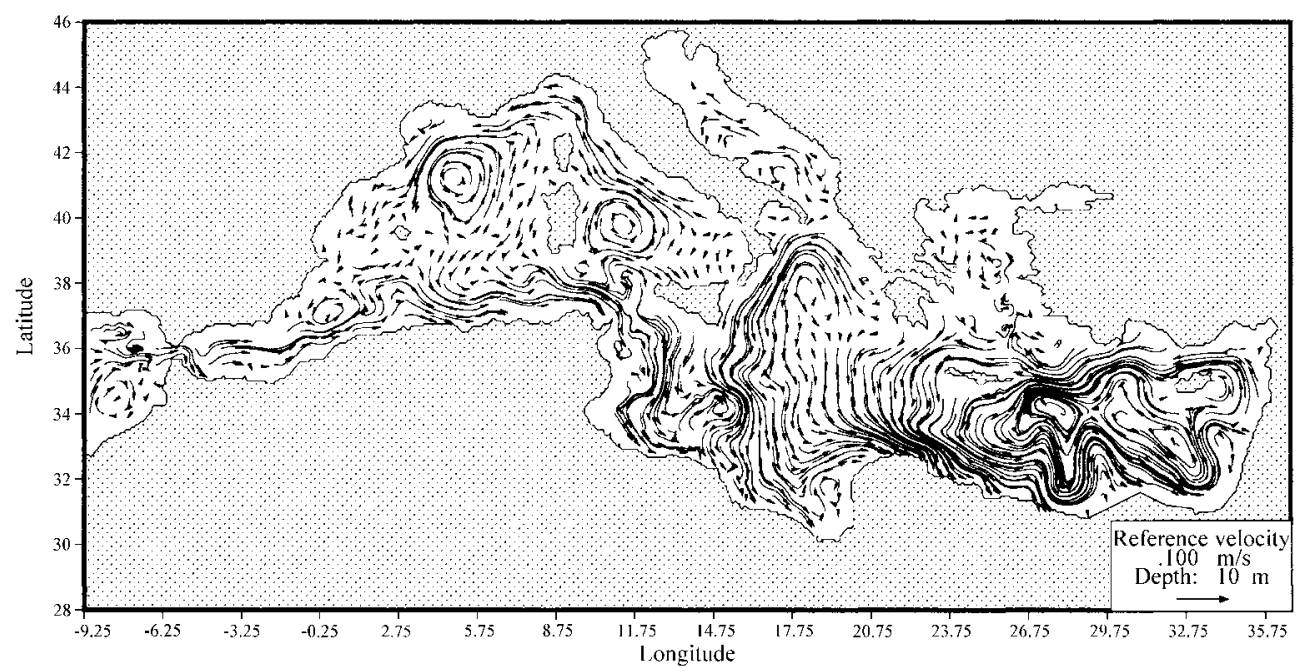

Fig. 15. Velocity fields March Average, experiment II.

similar, except for the CETIIS run with an unexplained high salinity in the Adriatic Sea.

\section{Conclusions}

Though the oceanographic relevance of the first experiment is not optimal (due to the forcing), at least the models exhibit a similar seasonal cycle and climatic drift. The drift can be controlled by using better forcing data, which was proven by the second experiment. In both cases, all models gave a satisfactory representation of the seasonal cycle of the circulation. It is interesting to note that more than $90 \%$ of the sea surface temperature variability can be explained by a seasonally varying EOF. This indicates the very strong signal of this cycle and gives some confidence of the model responses at this scale. It 


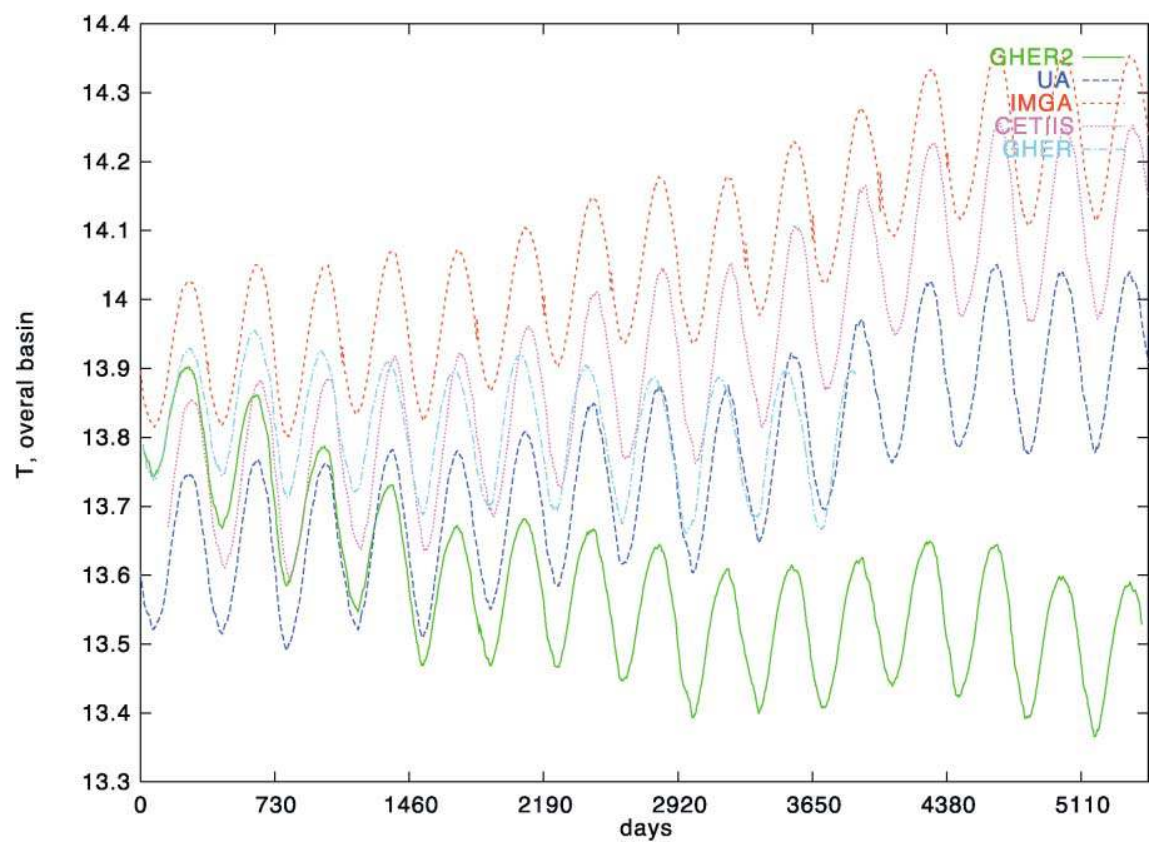

Fig. 16. Average temperature (in degrees celsius), experiment II. GHER2 corresponds to a variant of the normal GHER run, where a background surface relaxation on temperature was maintained at a very low level $(0.1 \mathrm{~m} /$ day $)$, indicating the strong impact of small changes in surface fluxes on budgets.

poses however the question to what extent interannual variability may be assessed with the models, since this signal would be rather small compared to the seasonal signal; a small error in the seasonal signal could be interpreted as an interannual signal. To disclose this conjecture it could be sufficient to calculate some EOF fields for other fields or 3D fields, to see if the amplitude of seasonal cycle decreases compared to the interannual variability.

But before analysing signals like interannual variations, we can already say that even the simulation of a strong signal asks for a well-designed model and a detailed model calibration. From the experiment it seems that the model behaviour depends on the modeller's skill as much as on the models (a model is here understood as the mathematical model and its computer implementations, without specified parameter values). This means that in a first order approach, the most important task is the correct setup of the model including its calibration (here, clearly the experience of the scientist was very helpful). For the models tested here, the most important calibration parameter was the vertical diffusion coefficient. In this case, the models with constant vertical diffusion coefficient had the largest changes in model responses when changing the calibration. Results of models with turbulent closure schemes were during the first runs already closer to the final run. Knowing that the implementation and tuning of the model took the most time, this would give turbulent closure models a slight advantage.

No model, however, clearly performs better than the others; some give a better signal of the variability, some conserve deep water characteristics better, etc.

No real outliers are visible either, except an initially very strong drift in the UIB-MOM version, which was reduced by modifying the vertical diffusion and a subbasin drift in the UA-POM model due to diffusion along $\sigma$-coordinates. Regarding horizontal diffusion, one can say that it was the next important calibration parameter, as long as it did not introduce strong artefacts related to the numerical grid-alignment with respect to natural stratification. Thus, the general classical recommendation to 


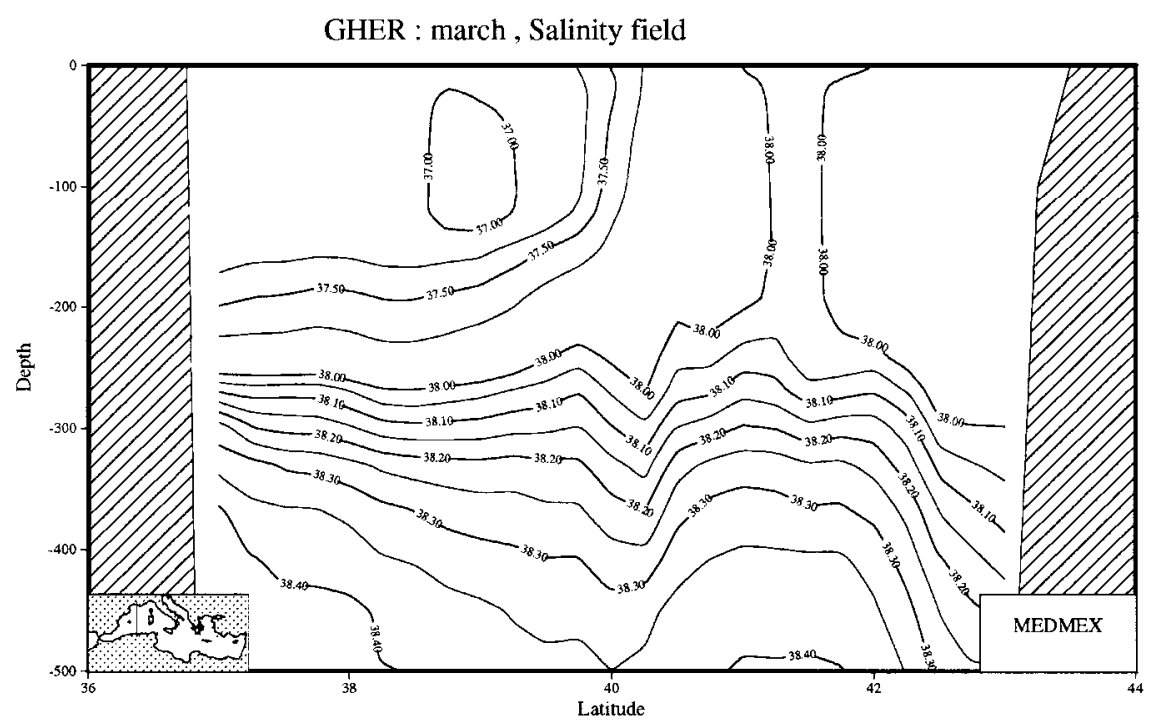

UA : march, Salinity field

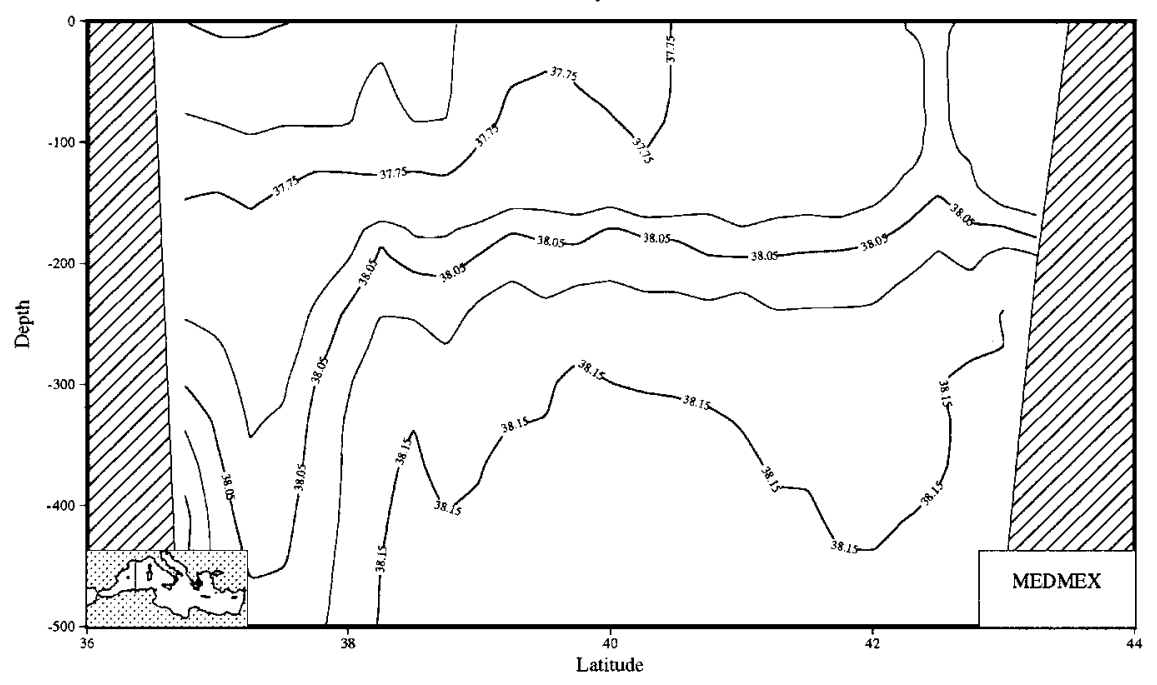

Fig. 17. Salinity section March Average, experiment II.

keep horizontal diffusion as small as possible is still valid.

Though the intercomparison was helpful in calibrating and correcting, a real benchmarking and skill assessment was not possible - a classical drawback of most intercomparison projects. This is probably due to the difficulty to choose among the large number of statistical methods for comparing model data when designing the intercomparison experiment. Since most of the intercomparison exercises cannot rerun the models once the results are provided for comparison, selecting the relevant statistics for comparison is a major challenge. In this respect as well, the absence of sufficiently large data sets limits the type of tools that can be used. Indeed, in our case most of the time integral quantities are compared, while vertical sections proved to be the most sensitive to model changes. Here, it would probably have been helpful to add a 
CETIIS : march, Salinity field

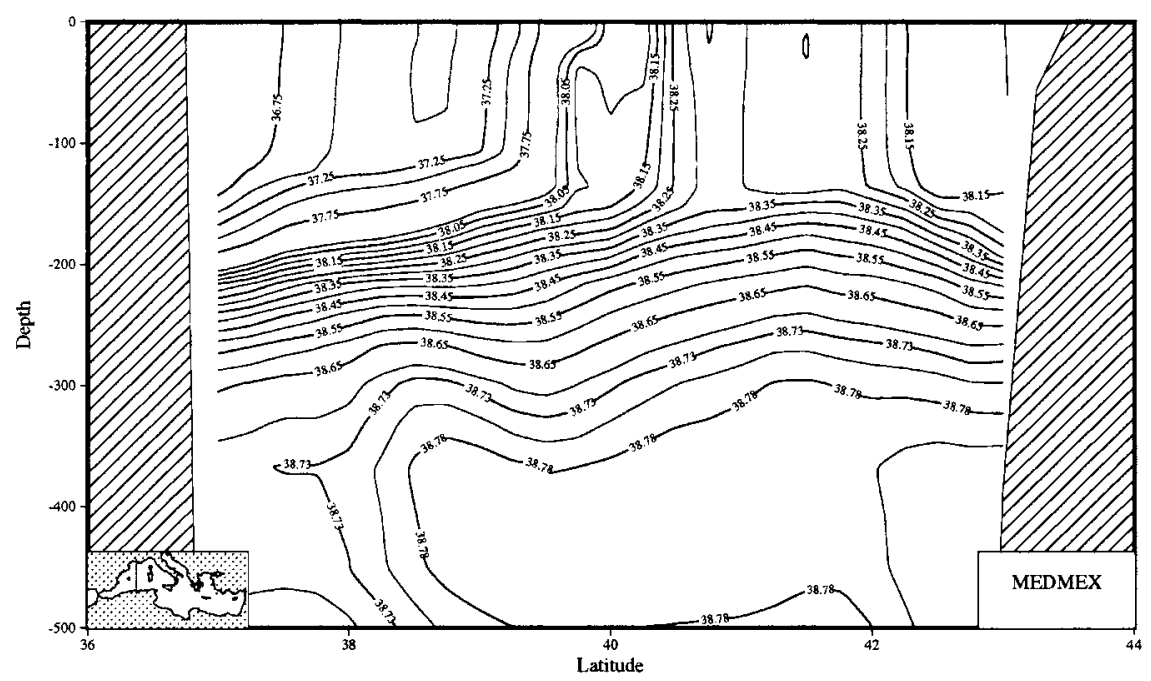

IMGA : march, Salinity field

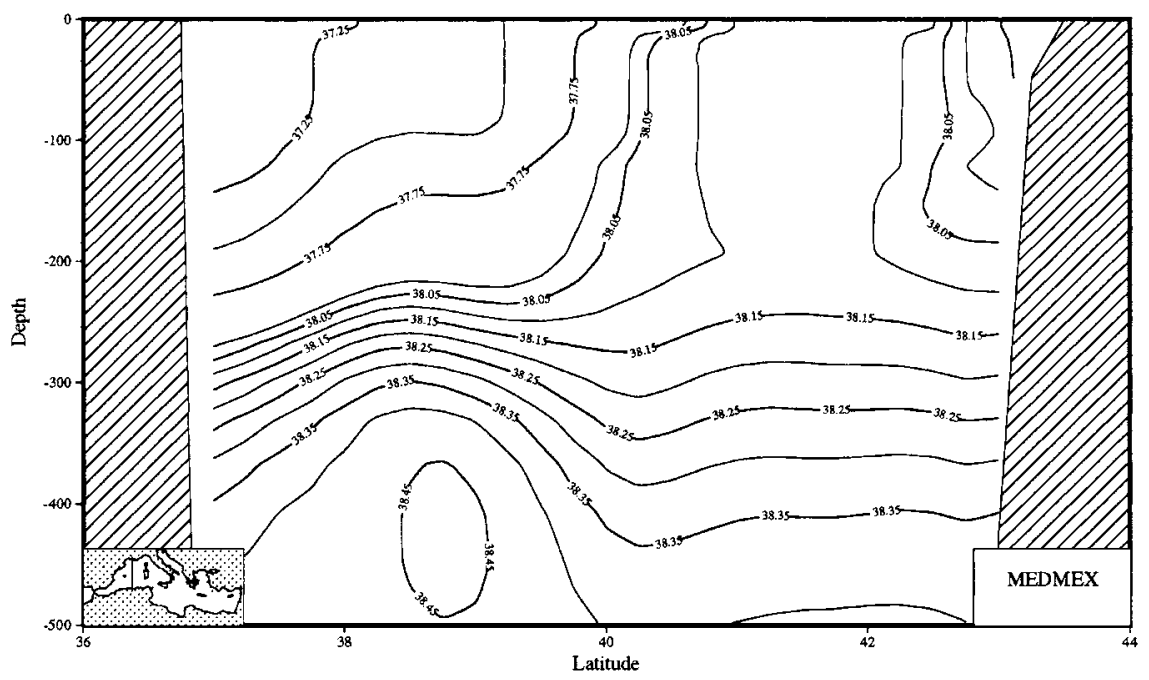

Fig. 18. Salinity section March Average, experiment II.

model intercomparison component on chemical tracer components (CFCs), in order to more rapidly analyse the mixing behaviour. Here again the practical problem of intercomparison shows up, i.e. which is the difficulty to add diagnostic outputs to the model after the simulations were performed.

From the present experiment, we suggest that systematic model intercomparison should be main- tained in any major modelling effort, as it offers the following advantages: reductions in errors, reduction of the time needed to calibrate the models, allowing more rapid detection of problems with forcing data and leading to model results to which some additional information has been added, i.e. the distance to other model results. Here, one could certainly consider the inclusion of several models into operational tools in 
Table 4

Percentage of variance explained by the corresponding mode

\begin{tabular}{llll}
\hline & EOF1 & EOF2 & EOF3 \\
\hline GHER & 94.11 & 1.56 & 1.18 \\
UA & 94.42 & 2.20 & 0.73 \\
IMGA & 94.88 & 1.68 & 0.51 \\
MODB & 98.03 & 0.86 & 0.32 \\
\hline
\end{tabular}

order to provide ensemble predictions not only based on a single model.

\section{Acknowledgements}

The authors wish to express their gratitude to all those who encouraged the establishment of the intercomparison experiment, in particular Prof. J. Nihoul, Dr. J. Oberhuber and Prof. W. Roether for their suggestions during the preparation of the project. Two anonymous reviewers made constructive comments and are acknowledged.

The model intercomparison was supported by the European Union (MEDMEX contract MAS2-CT940107 and MATER contract MAS3-CT96-0051).
The Alexander von Humboldt foundation and the FNRS are acknowledged for giving the opportunity to the first author to work on this topic. FNR (FRFC $2.4592 .00 \mathrm{~F})$

\section{References}

Alvarez, A., Tintore, J., Holloway, G., Eby, M., Beckers, J.-M., 1994. Effect of topographic stress on circulation in the Western Mediterranean. Journal of Geophysical Research 99, 1605316064.

Arakawa, A., Lamb, V., 1977. Computational design of the basic dynamical processes of the UCLA general circulation model. Methods in Computational Physics, vol. 17. Academic Press, New York, pp. 1-337.

Baptista, A., Adams, E., Gresho, P., 1995. Benchmarks for the transport equation; the convection-diffusion forum and beyond. In: Lynch, D., Davies, A. (Eds.), Quantitative Skill Assessment for the Coastal Ocean Models. Coastal and Estuarine Studies, vol. 47. AGU, Washington, DC, pp. 241-268.

Beckers, J.-M., 1991. Application of a 3D model to the Western Mediterranean. Journal of Marine Systems 1, 315-332.

Beckers, J.-M., 1999. On some stability properties of the discretization of the damped propagation of shallow-water inertiagravity waves on the Arakawa B-grid. Ocean Modelling 1, $53-69$.

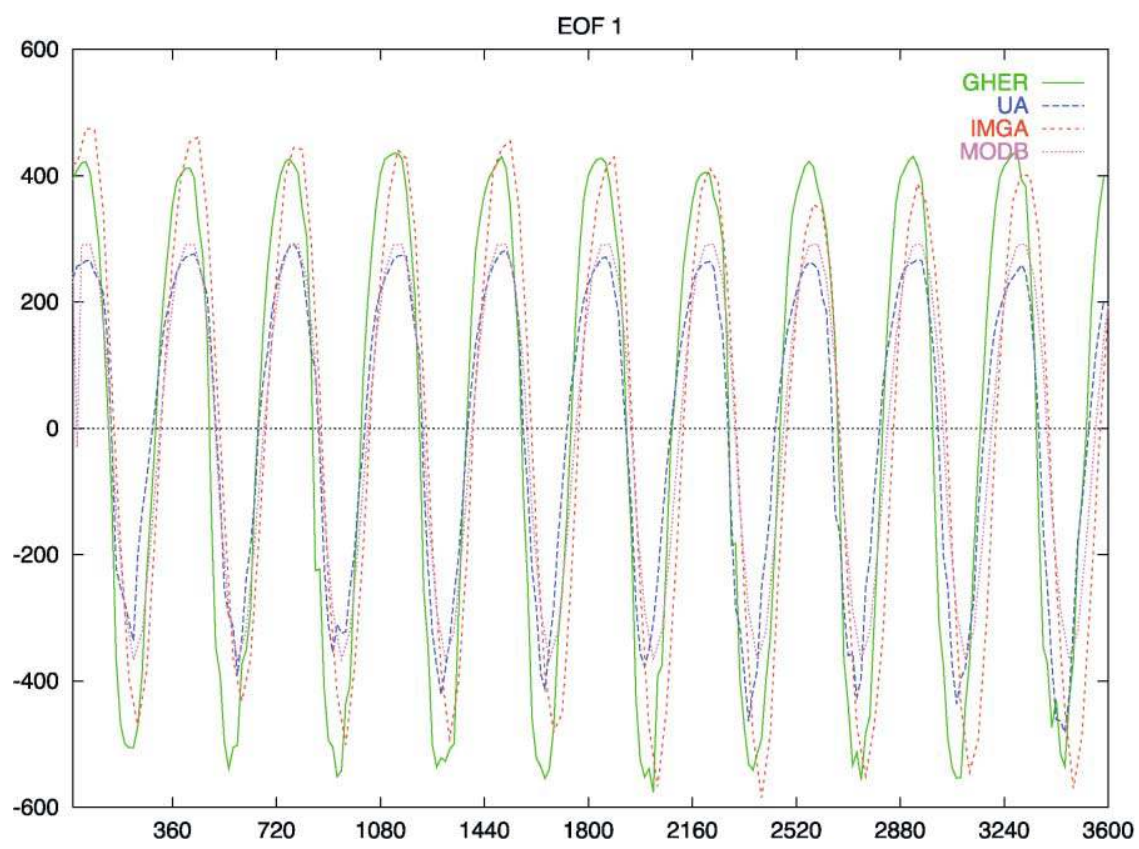

Fig. 19. Amplitude evolution of the first EOF. 

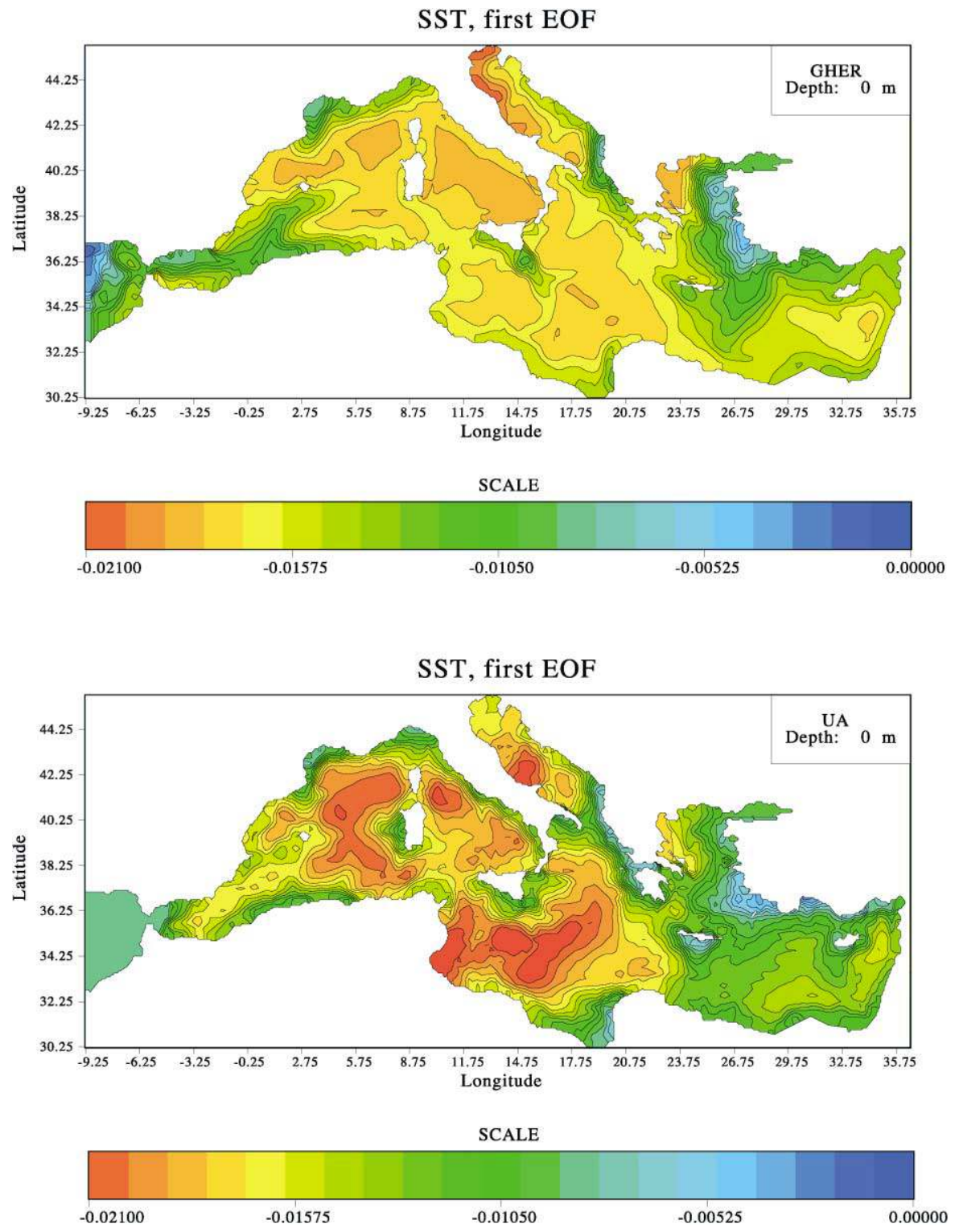

Fig. 20. First SST EOF.

Beckers, J.-M., Deleersnijder, E., 1993. Stability of a FBTCS scheme applied to the propagation of shallow-water inertiagravity waves on various space grids. Journal of Computational Physics 108, 95-104.

Beckers, J., et al., 1996. First annual report, Mediterranean Models Evaluation Experiment.

Brasseur, P., Beckers, J.-M., Brankart, J.-M., Schoenauen, R., 1996. Seasonal temperature and salinity fields in the Mediterranean Sea: climatological analyses of a historical data set. Deep-Sea Research 43, 159-192.
Crepón, M., Martel, F., 1995. EUROMODEL II: the hydrodynamics of the Western Mediterranean. In: Weydert, M., Lipiatou, E., Goñi, R., Fragakis, C., Bohle-Carbonell, M., Barthel, K.-G. (Eds.), Second Mast Days and Euromar Market. Project Reports, vol. 1. Commission of the European Communities, Brussels, pp. 480-493.

Davies, A., Xing, J., 1995. An intercomparison and validation of a range of turbulence closure schemes used in three dimensional tidal models. In: Lynch, D., Davies, A. (Eds.), Quantitative Skill Assessment for the Coastal Ocean Models. Coastal 

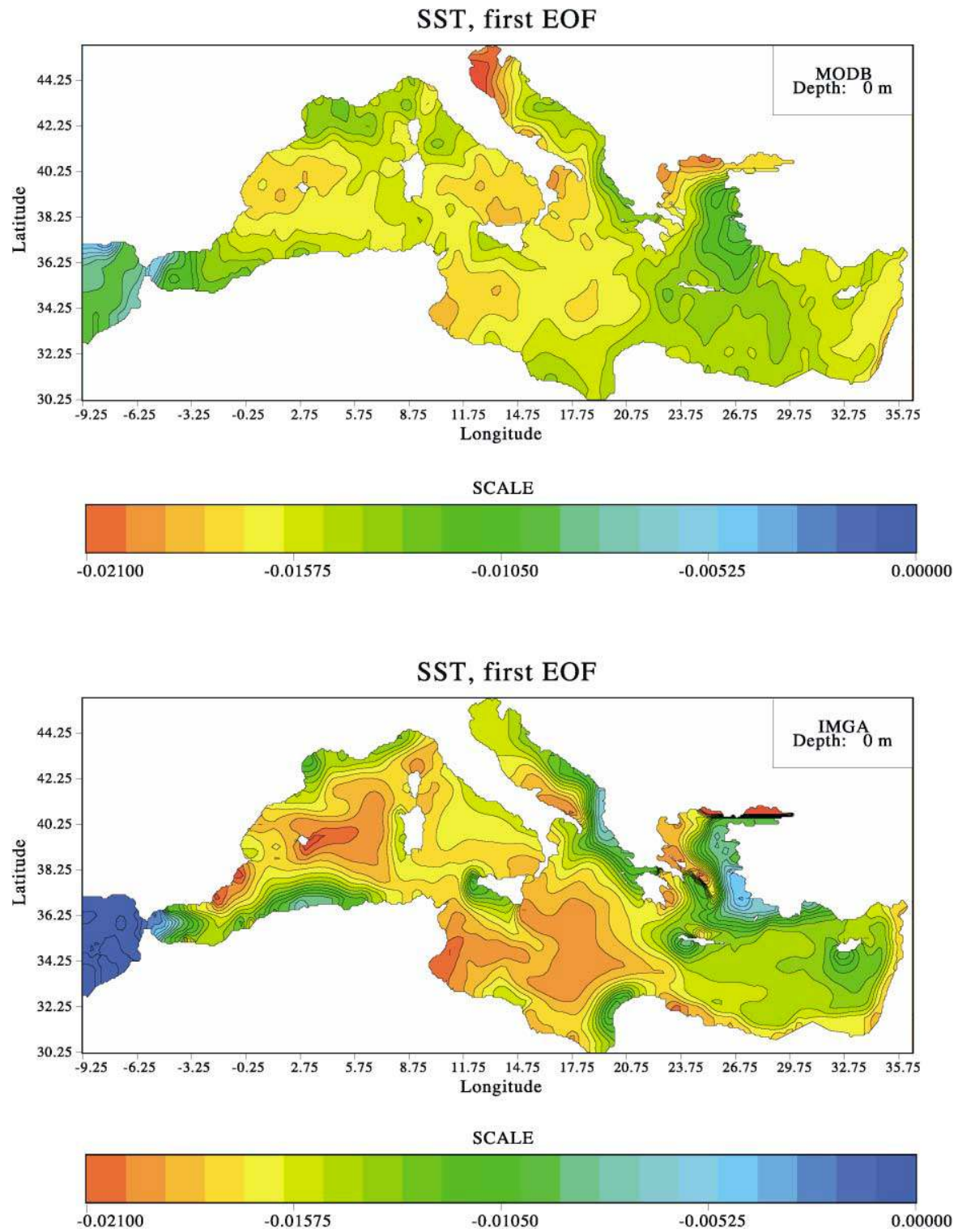

Fig. 21. First SST EOF.

and Estuarine Studies, vol. 47. AGU, Washington, DC, pp. $71-95$.

Dee, P., 1995. A pragmatic approach to model validation. In: Lynch, D., Davies, A. (Eds.), Quantitative Skill Assessment for the Coastal Ocean Models. Coastal and Estuarine Studies, vol. 47. AGU, Washington, DC, pp. 1-13.

Demirov, E., Pinardi, N., 2002. Simulation of the Mediterranean Sea circulation from 1979 to 1993 . Part I: The interannual variability. Journal of Marine Systems 33-34, 23-50 (this issue).
Durran, D., 1999. Numerical methods for wave equations in geophysical fluid dynamics. Texts in Applied Mathematics, vol. 32. Springer.

EUROMODEL group, 1995. Progress from 1989 to 1992 in understanding the circulation of the Western Mediterranean. Oceanologica Acta 18, 255-271.

Gates, L., Boyle, J., Covey, C., Dease, G., Doutriaux, C., Drach, R., Fiorino, M., Geckler, P., Hnilo, J., Marlais, S., Phillips, T., Potter, G., Santer, B., Sperber, K., Taylor, K., Williams, D., 1999. 
An overview of the results of the atmospheric model intercomparison project (AMIP I). Bulletin of the American Meteorological Society 80, 29-55.

Griffies, S., Böning, C., Bryan, F., Chassignet, E., Gerdes, R., Hasumi, H., Hirst, A., Treguier, A.-M., Webb, D., 1999. Developments in ocean climate modeling. World climate research programme/world ocean circulation experiment working group on ocean model development. Ocean Modelling 2, 123-192.
Haidvogel, D., Beckmann, A., 1998. Numerical models of the coastal ocean. The Sea 10, 457-482.

Haines, K., Wu, P., 1998. GCM studies of intermediate and deep waters in the Mediterranean. Journal of Marine Systems 18 (1-3), 197-214.

Hellerman, S., Rosenstein, M., 1983. Normal monthly winds stress over the world ocean with error estimates. Journal of Physical Oceanography 13, 1093-1104.

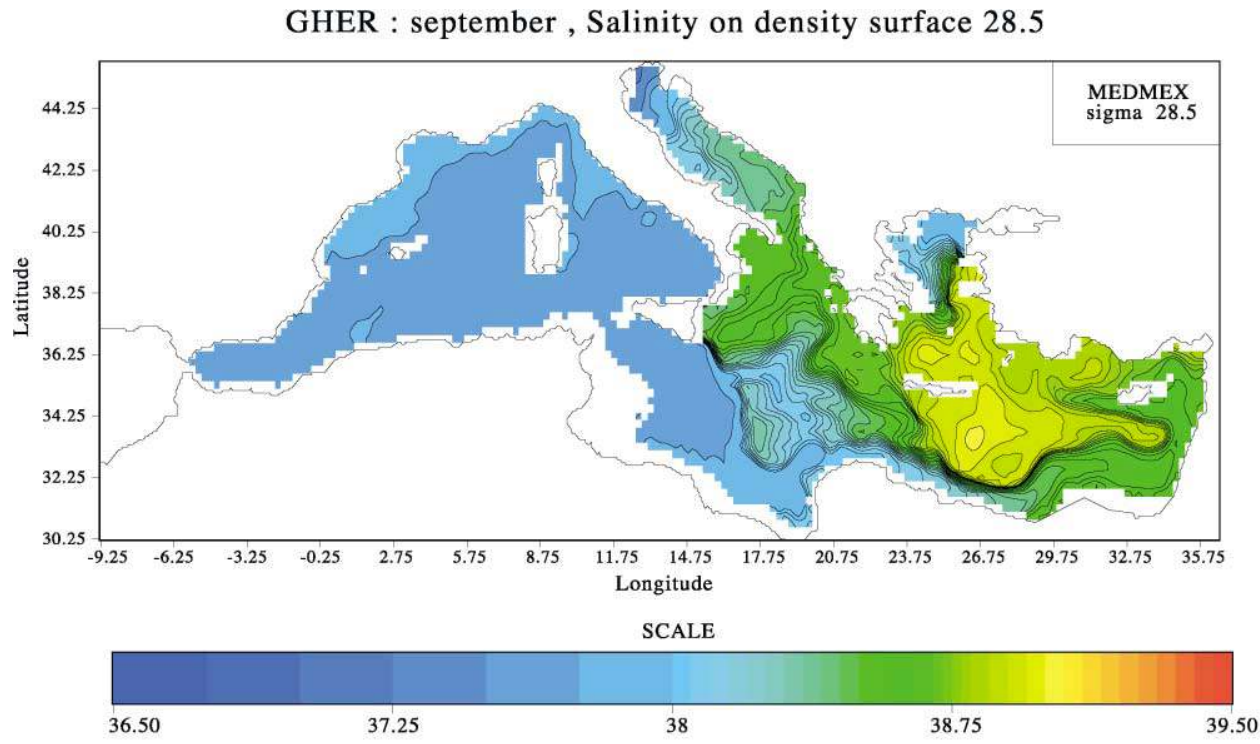

UA : september, Salinity on density surface 28.5

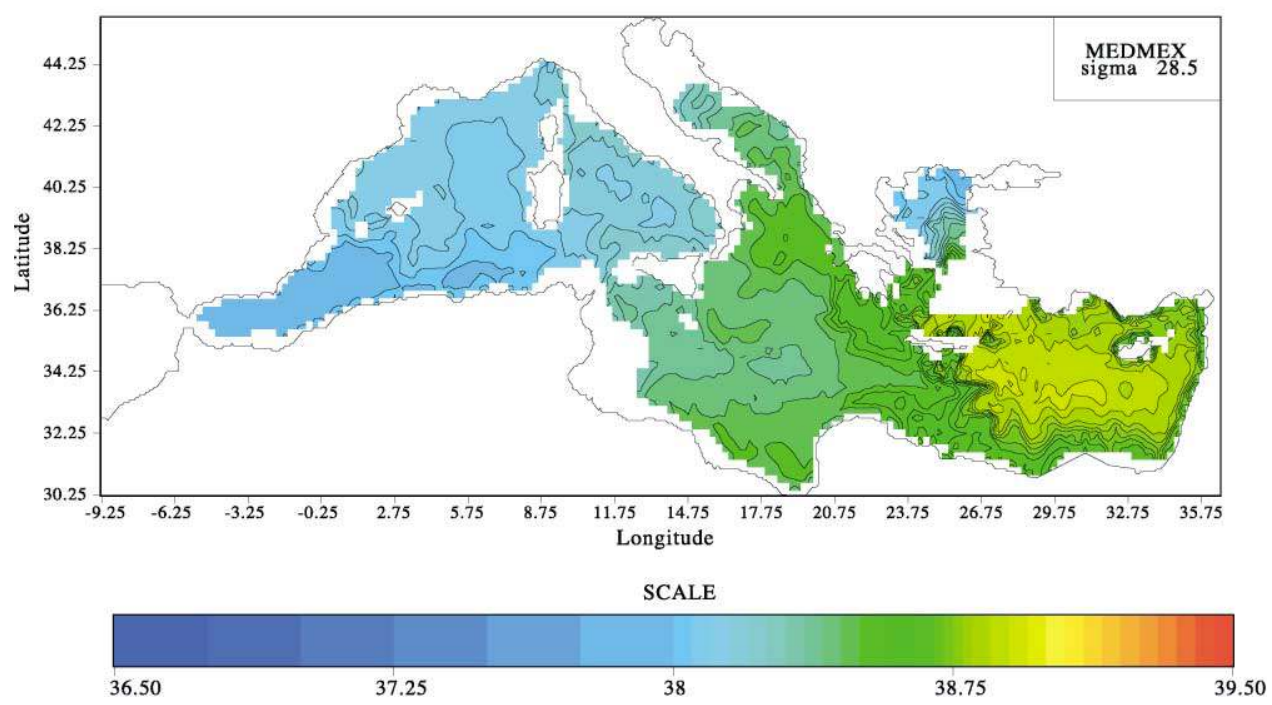

Fig. 22. Salinity September average, experiment II, isopycnal 28.5. MODBISO corresponds to a climatological data analysis performed directly in isopycnal space. 


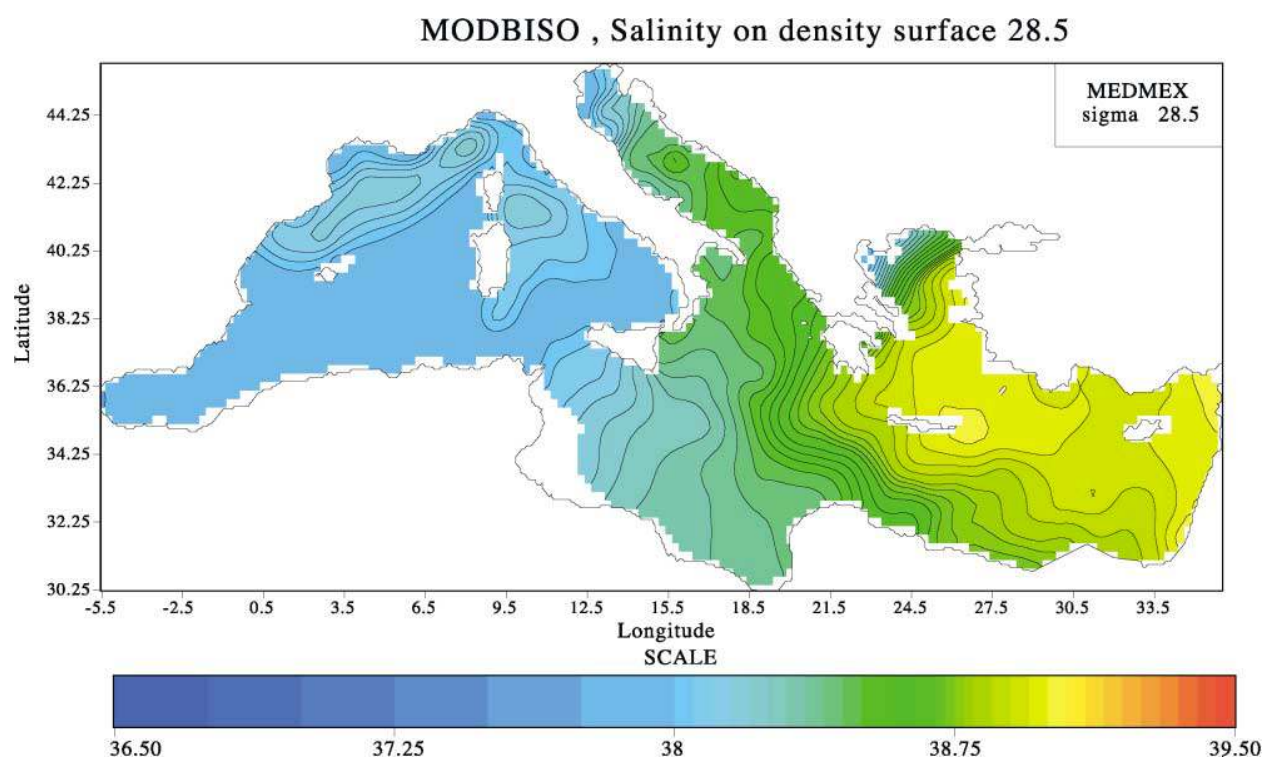

Fig. 22 (continued).

Herbaut, C., Mortier, L., Crepòn, M., 1996. A sensitivity study of the general circulation of the Western Mediterranean Sea: Part I. The response to density forcing through the straits. Journal of Physical Oceanography 26, 65-84.

Herbaut, C., Cordron, F., Crepòn, M., 1998. Separation of a coastal current at a strait level: case of the strait of Sicily. Journal of Physical Oceanography 28, 1346-1362.

Jaeger, L., 1976. Monthly precipitation maps for the entire earth (in German). Technical Report 18, Ber. Deutschen Wetterdienstes, $38 \mathrm{pp}$.

James, I., 1996. Advection schemes for shelf sea models. Journal of Marine Systems 8, 237-254.

Killworth, P.D., Stainforth, D., Webb, D., Paterson, S., 1991. The development of a free-surface Bryan-Cox-Semtner ocean model. Journal of Physical Oceanography 21, 1333-1348.

Lascaratos, A., Williams, R., Tragou, E., 1993. A mixed layer study of the formation of Levantine intermediate water. Journal of Geophysical Research 98, 14739-14749.

MERMAIDS, 1998. Mediterranean eddy resolving and interdisciplinary studies (MERMAIDS). In: Pinardi, N., Roether, W. (Eds.), Journal of Marine Systems, vol. 18. Elsevier, Amsterdam, pp. 1 312 , special issue.

Myers, P.G., Keith, H., 2000. Seasonal and interannual variability in a model of the Mediterranean under derived flux forcing. Journal of Physical Oceanography 30, 1069-1082.

Nittis, K., Lascaratos, A., 1999. Personal communication.

Pinardi, N., 1995. Mediterranean eddy resolving interdisciplinary studies. In: Weydert, M., Lipiatou, E., Goñi, R., Fragakis, C., Bohle-Carbonell, M., Barthel, K.-G. (Eds.), Second Mast Days and Euromar Market. Project Reports, vol. 1. Commission of the European Communities, Brussels, pp. 433-451.
Proctor, R., 1995. North sea model advection-dispersion study (NOMADS). In: Weydert, M., Lipiatou, E., Goñi, R., Fragakis, C., Bohle-Carbonell, M., Barthel, K.-G. (Eds.), Second Mast Days and Euromar Market. Project Reports, vol. 1. Commission of the European Communities, Brussels, pp. $170-181$.

Røed, L., Hacket, B., Gjevik, B., Eide, L., 1995. A review of the MetOcean MOdeling Project (MOMOP) Part 1: model comparison study. In: Lynch, D., Davies, A. (Eds.), Quantitative Skill Assessment for Coastal Ocean Models. Coastal and Estuarine Studies, vol. 47. AGU, Washington, DC, pp. 373-396.

Roether, W., Klein, B., Beitzel, V., Manca, B., 1998. Property distributions and transient-tracer ages in Levantine intermediate water in the Eastern Mediterranean. Journal of Marine Systems 18 (1-3), 71-88.

Roussenov, V., Stanev, E., Pinardi, N., 1995. A seasonal model of the Mediterranean Sea general circulation. Journal of Geophysical Research 100, 13515.

Slørdal, L.H., Martinsen, E.A., Blumberg, A.F., 1994. Modeling the response of an idealized coastal ocean to a traveling storm and to flow over topography. Journal of Physical Oceanography 24, $1689-1705$.

Stratford, K., Haines, K., 2002. Modelling changes in Mediterranean thermohaline circulation 1987-1995. Journal of Marine Systems 33-34, 51-62 (this issue).

Vested, H., Nielsen, J., Jensen, H., Kristensen, K., 1995. Skill assessment of an operational hydrodynamical forecast system for the North Sea and Danish Belt. In: Lynch, D., Davies, A. (Eds.), Quantitative Skill Assessment for Coastal Ocean Models. Coastal and Estuarine Studies, vol. 47. AGU, Washington, DC, pp. $373-396$. 


\section{CETIIS : september, Salinity on density surface 28.5}

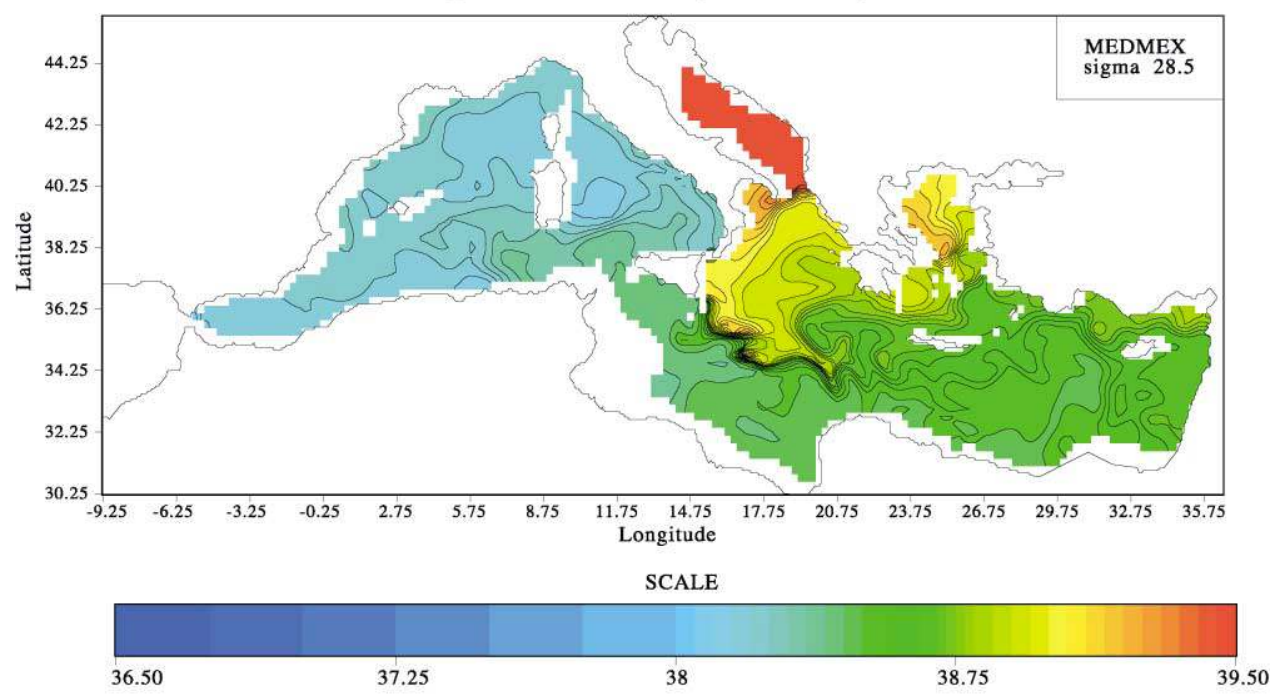

IMGA : september, Salinity on density surface 28.5

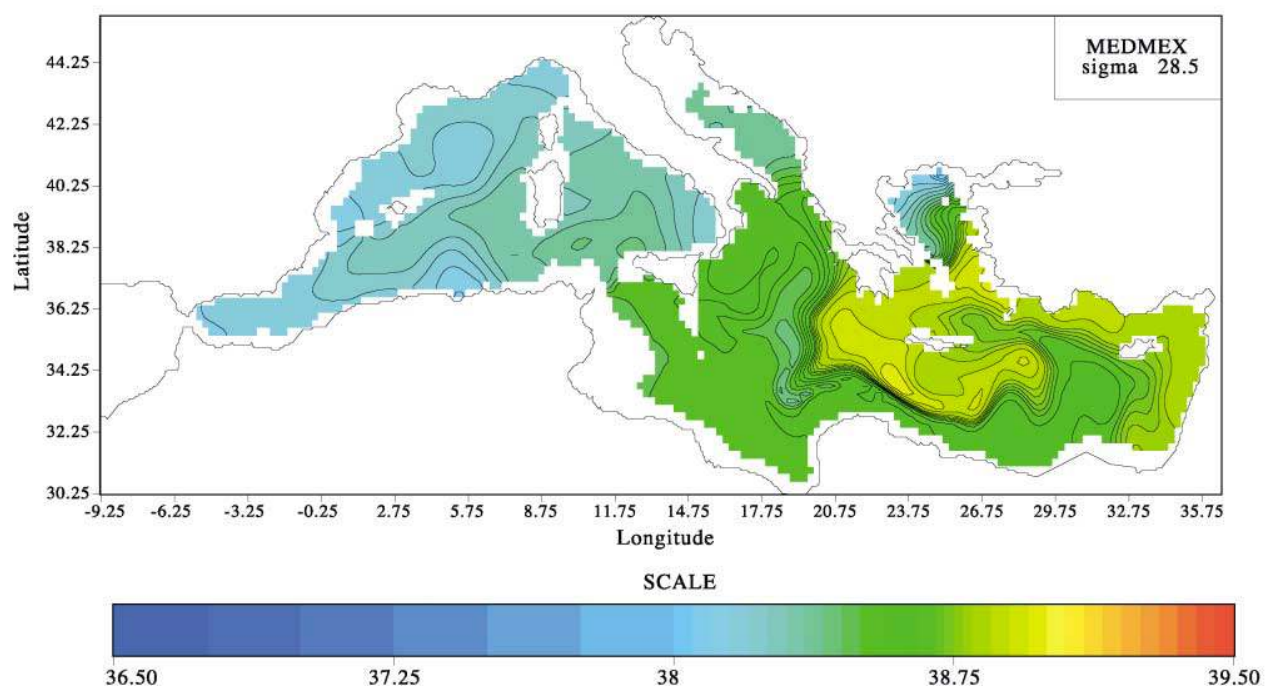

Fig. 23. Salinity September average, experiment II, isopycnal 28.5. MODBISO corresponds to a climatological data analysis performed directly in isopycnal space.

Wajsowicz, R., 1986. Free planetary waves in finite-difference numerical models. Journal of Physical Oceanography 16, $773-$ 789.

Werner, F., 1995. A field test case for tidally flows forced flows: a review of the tidal flow forum. In: Lynch, D., Davies, A. (Eds.), Quantitative Skill Assessment for Coastal Ocean Models. Coast- al and Estuarine Studies, vol. 47. AGU, Washington, DC, pp. 269-283.

Zavatarelli, M., Mellor, G., 1995. A numerical study of the Mediterranean Sea circulation. Journal of Physical Oceanography 25, $1384-1414$. 